\title{
The Unique Pharmacological and Pharmacokinetic Profile of Teneligliptin: Implications for Clinical Practice
}

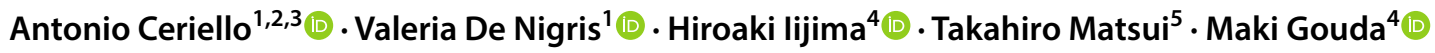

Published online: 13 April 2019

(c) The Author(s) 2019

\begin{abstract}
Teneligliptin is a dipeptidyl peptidase-4 (DPP-4) inhibitor that was approved for the treatment of type 2 diabetes mellitus (T2DM) in Japan and Korea and is being researched in several countries. Teneligliptin is a potent, selective, and long-lasting DPP-4 inhibitor with a $t_{1 / 2}$ of approximately $24 \mathrm{~h}$ and unique pharmacokinetic properties: it is metabolized by cytochrome P450 (CYP) 3A4 and flavin-containing monooxygenase 3 (FMO3), or excreted from the kidney in an unchanged form. Because of its multiple elimination pathways, dose adjustment is not needed in patients with hepatic or renal impairment, and it is considered to have a low potential for drug-drug interactions. Clinical studies and postmarketing surveillance show that teneligliptin, administered as monotherapy and/or in combination with antihyperglycemic agents, is effective and well tolerated in T2DM patients, including in elderly patients and those with renal impairment. Furthermore, teneligliptin has antioxidative properties, which induce the antioxidant cascade, as well as $\cdot \mathrm{OH}$ scavenging properties. In addition, it has shown endothelial protective effects in several non-clinical and clinical studies. From its unique profile and clinical data, teneligliptin represents a potential therapeutic option in a wide variety of patients, including elderly diabetic patients and those with renal impairment. The fixed-dose combination (FDC) tablet of teneligliptin and canagliflozin has been approved in Japan; this is the first FDC tablet of a DPP-4 inhibitor and sodium glucose co-transporter 2 inhibitor in Japan, and the third globally. The FDC tablet may also provide additional prescribing and adherence benefits.
\end{abstract}

\section{Introduction}

The prevalence of type 2 diabetes mellitus (T2DM) is increasing worldwide. In 2017, it was estimated that 451 million people aged 18-99 years had diabetes, and that the disease was responsible for approximately 5.0 million deaths in that year [1]. There are different trends in diabetes prevalence by age group, income, and region. For example,

Antonio Ceriello

ACERIELL@clinic.cat

1 Institut d'Investigacions Biomèdiques August Pi i Sunyer (IDIBAPS), Rosselló, 149-153, 08036 Barcelona, Spain

2 Istituto di Ricovero e Cura a Carattere Scientifico (IRCCS) MultiMedica, Milan, Italy

3 Centro de Investigación Biomédica en Red de Diabetes y Enfermedades Metabólicas Asociadas (CIBERDEM), Barcelona, Spain

4 Ikuyaku. Integrated Value Development Division, Mitsubishi Tanabe Pharma Corporation, Tokyo, Japan

5 Ikuyaku. Integrated Value Development Division, Mitsubishi Tanabe Pharma Corporation, Osaka, Japan in low- and middle-income countries, diabetes predominantly affects individuals aged $\leq 65$ years (prevalence $88 \%$ and $77 \%$, respectively); however, in high-income countries, almost half (44\%) of all individuals with diabetes are aged $>65$ years [1].

In Japan, more than $60 \%$ of T2DM patients are estimated to be over 65 years of age [2]. Another report suggested that approximately 8.8 million people in Japan had T2DM in 2015, with the disease affecting approximately $20 \%$ of men and $10 \%$ of women aged $\geq 60$ years [3]. With the population aging in Japan, the prevalence of T2DM is predicted to rise substantially over the next two decades, affecting 9.7 million people by 2030 [3]. In elderly T2DM patients, careful treatment is needed because of the high risk of hypoglycemia and drug adverse events (AEs) due to the altered pharmacokinetic profile associated with aging and polypharmacy [4-6]. Therefore, the treatment of elderly T2DM patients is a growing problem in several countries, including Japan.

Hyperglycemia is an important cause of morbidity and mortality in T2DM and is associated with both macrovascular (coronary artery disease, peripheral arterial disease, and stroke) and microvascular (diabetic nephropathy, neuropathy, 


\section{Key Points}

Teneligliptin is a potent, selective, and long-lasting DPP-4 inhibitor with a unique pharmacokinetic profile (multiple elimination pathways); no dose adjustment is needed in patients with hepatic or renal impairment and it is considered to have a low potential for drug-drug interactions.

Teneligliptin has antioxidative properties and has shown endothelial protective effects in several non-clinical and clinical studies.

Teneligliptin provides a therapeutic option for a broad range of T2DM patients, including elderly subjects and those with renal impairment.

and retinopathy) complications [7]. The endothelium plays a crucial role in developing diabetic complications: long-term hyperglycemia-induced oxidative stress, non-enzymatic glycation of proteins, epigenetic changes, and chronic inflammation lead to a reduction in vascular endothelial function $[8,9]$, perpetuating cellular environment changes (metabolic memory) $[8,10]$ and micro- or macrovascular events. From a clinical perspective, this theory supports the importance of early treatment to prevent diabetic complications $[10,11]$.

Dipeptidyl peptidase-4 (DPP-4) inhibitors enhance insulin secretion and suppress glucagon secretion in a blood glucose-dependent manner by increasing levels of endogenous intact glucagon-like peptide-1 (GLP-1) and glucose-dependent insulinotropic polypeptide, thereby reducing blood glucose levels with a low risk of hypoglycemia [12-14]. Studies have shown that DPP-4 inhibitors have postprandial glucose (PPG) lowering effects in patients with T2DM, reducing glycated hemoglobin $(\mathrm{HbA} 1 \mathrm{c})$ by approximately $0.5-1.0 \%$, with greater glucose-lowering efficacy observed in Asian versus non-Asian individuals [15-17]. DPP-4 inhibitors are generally considered to have a neutral effect on cardiovascular events in high-risk patients $[18,19]$.

Metformin is the first-line treatment for T2DM in Western countries [20], while DPP-4 inhibitors have gained substantial market share as second- or third-line treatment options [21]. In contrast, DPP-4 inhibitors are used extensively in Japan. Over $70 \%$ of patients who receive antidiabetic drugs are prescribed a DPP- 4 inhibitor. Of these patients, $60 \%$ are prescribed a DPP-4 inhibitor as first-line therapy, according to the Japan Medical Data Center claims database [13, 22]. Nine DPP-4 inhibitors are approved in Japan. Several differences exist between the DPP-4 inhibitors in terms of their pharmacokinetic profiles and specific physical properties. These differences relate to the need for dose adjustment, their drug-drug interaction profiles, or their pleiotropic effects [14].
Teneligliptin, a DPP-4 inhibitor, was approved for the treatment of T2DM in Japan in 2012 and in Korea in 2014, and is being researched in several countries [23]. The approved dose of teneligliptin is $20 \mathrm{mg}$ once daily. In Japan, the dosage can be increased to $40 \mathrm{mg} / \mathrm{day}$, with close monitoring of the clinical course if efficacy is insufficient [24, 25]. In July 2017, Japan's first DPP-4 inhibitor/sodium glucose co-transporter 2 (SGLT2) inhibitor combination drug, a fixed-dose combination (FDC) tablet of teneligliptin/canagliflozin, was approved for the treatment of T2DM.

This review summarizes non-clinical, pharmacokinetic, and clinical data for teneligliptin, and discusses the role of teneligliptin in clinical practice, in light of the drug's novel chemical structure, pharmacokinetic profile, and pleiotropic effects.

PubMed and Scopus searches were performed using the key word 'teneligliptin'. In addition, the prescribing information for teneligliptin and the other DPP-4 inhibitors was searched via the Pharmaceuticals and Medical Devices Agency (PMDA) home page using the drug name (e.g. teneligliptin) or brand name (e.g. Tenelia) as keywords.

\section{Chemical Structure}

Teneligliptin is a prolylthiazolidine-based DPP-4 inhibitor characterized by a unique, rigid, 'J-shaped' structure of five consecutive rings (Fig. 1) [25-27]. DPP-4 inhibitors are categorized into three groups, based on interactions with DPP-4 binding subsites. Like sitagliptin, teneligliptin is a class 3 DPP-4 inhibitor and binds to S1, S2, and S2 extensive subsites on DPP-4; however, teneligliptin demonstrates fivefold higher activity than sitagliptin. While sitagliptin and teneligliptin appear to bind to subsites in the same manner, there are three potential factors that may account for differences in potency. First, the unique, rigid 'J-shaped' structure of teneligliptin, formed by five rings, leads to a small entropy loss upon binding to DPP-4 [27]. Second, the affinity of teneligliptin to the S2 subsite of DPP-4 is derived from the formation of a hydrogen bond between the carbonyl group of teneligliptin and the side chain of Asn710 at the S2 subsite [27]. Finally, teneligliptin binds with the $\mathrm{S} 2$ extensive subsite of DPP-4 via strong hydrophobic interactions mediated by an 'anchor lock domain' [25, 27]. These interactions may be related to the potency of inhibition and the duration of action of teneligliptin observed in vivo [27].

\section{Pharmacological Properties}

\subsection{In Vitro Studies}

Teneligliptin is a potent, selective, and long-lasting DPP-4 inhibitor that has approximately 700 - to 1500 -fold greater 


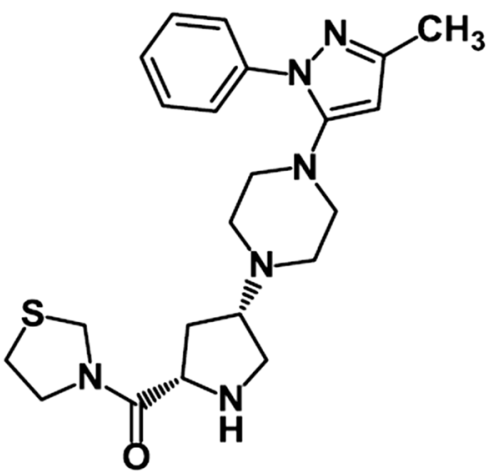

- $2 \frac{1}{2} \mathrm{HBr} \cdot \mathrm{xH}_{2} \mathrm{O}$

Fig. 1 Chemical structure of teneligliptin

affinity for DPP-4 than other DPP enzymes, such as DPP-8 and DPP-9 [26]. Teneligliptin inhibits recombinant human DPP-4 and human plasma DPP-4 in a concentration-dependent manner: concentrations producing half maximal inhibition $\left(\mathrm{IC}_{50}\right)$ are $0.889 \mathrm{nmol} / \mathrm{L}$ and $1.75 \mathrm{nmol} / \mathrm{L}$, respectively [28]. In these respects, teneligliptin is more potent than sitagliptin $(6.74 \mathrm{nmol} / \mathrm{L}$ and $4.88 \mathrm{nmol} / \mathrm{L}$, respectively) and vildagliptin $(10.5 \mathrm{nmol} / \mathrm{L}$ and $7.67 \mathrm{nmol} / \mathrm{L}$, respectively), as demonstrated by lower $\mathrm{IC}_{50}$ values [28].

\subsection{In Vivo Studies}

In rats, single oral administration of teneligliptin inhibited plasma DPP-4 in a dose-dependent manner, with a median effective dose of $0.41 \mathrm{mg} / \mathrm{kg}$, compared with 27.3 and $12.8 \mathrm{mg} / \mathrm{kg}$ for sitagliptin and vildagliptin, respectively [28]. At $24 \mathrm{~h}$ after drug administration, inhibition of DPP-4 persisted with teneligliptin $10 \mathrm{mg} / \mathrm{kg}$ ( $\geq 50 \%$ inhibition), but did not persist with sitagliptin or vildagliptin $100 \mathrm{mg} / \mathrm{kg}$ ( $<3 \%$ and $<15 \%$ inhibition, respectively) [28]. The effect of teneligliptin in an oral mixed meal tolerance test showed that teneligliptin $0.1 \mathrm{mg} / \mathrm{kg}$ had nearly maximum effects for reducing glucose excursion and increasing active GLP-1/ insulin. Plasma DPP-4 inhibition was $\geq 40 \%$ for the entire treatment period of the oral mixed meal tolerance test, suggesting that $40 \%$ DPP-4 inhibition was required for sufficient efficacy [28].

The effects of teneligliptin on hyperglycemia and hypertriglyceridemia were evaluated in Zucker fatty rats [28]. A single dose of teneligliptin $1 \mathrm{mg} / \mathrm{kg}$ reduced PPG, free fatty acid, and triglyceride excursions after carbohydrate and fat loading. After repeated administration of teneligliptin for 2 weeks, glucose excursions after carbohydrate loading were reduced, as were non-fasting levels of free fatty acids and triglycerides [28].

\section{Pharmacokinetic Properties}

\subsection{Non-Human Study}

Oral administration of teneligliptin $(0.1,0.3$, or $1.0 \mathrm{mg} / \mathrm{kg})$ in rats showed rapid absorption, with mean peak plasma concentration $\left(t_{\max }\right)$ reached in $0.75-0.88 \mathrm{~h} \mathrm{[26].} \mathrm{After} \mathrm{oral}$ administration of $\left[{ }^{14} \mathrm{C}\right]$ teneligliptin to Sprague-Dawley rats, teneligliptin was predominantly distributed in the kidney and liver, followed by the lung, spleen, and pituitary gland [29]. It was reported that tissue DPP-4 activity was greatest in the kidney, followed by the lung, adrenal gland, jejunum, and liver [30]. The elimination of $\left[{ }^{14} \mathrm{C}\right]$ teneligliptin from tissues with high DPP-4 activity (kidney, liver, and lung) was slower in wild-type Fisher rats than in DPP-4-deficient rats, although there was no marked difference in low DPP-4 activity tissues (the heart and pancreas). This suggests that the high binding affinity of teneligliptin for DPP-4 has some influence on tissue distribution of the drug [29]. Among DPP-4 inhibitors, teneligliptin and linagliptin have high tissue distribution properties, especially in the kidney. The hydrophobic properties of both drugs may influence the high tissue distribution [29].

\subsection{Healthy Subjects}

Pharmacokinetic data for teneligliptin (20 and $40 \mathrm{mg}$ ) in Japanese healthy subjects are outlined in Table 1. Single oral doses of teneligliptin $(2.5,10,20,40,80$, and $160 \mathrm{mg})$ or placebo were administered under fasting conditions, and dose-dependent increases in the maximal plasma concentration $\left(C_{\max }\right)$ and area under the plasma concentration-time curve (AUC) of teneligliptin were observed. The $t_{\max }$ and mean elimination half-life $\left(t_{1 / 2}\right)$ of teneligliptin $20 \mathrm{mg}$ were 1.8 and $24.2 \mathrm{~h}$, respectively. After repeated doses of teneligliptin 20 or $80 \mathrm{mg}$, no remarkable changes were observed in the pharmacokinetic profile, and teneligliptin reached steady state by day 7 [24]. The pharmacokinetic profile did not differ between Japanese and Caucasian subjects [24, 31, 32].

The mass balance study using $\left[{ }^{14} \mathrm{C}\right]$ teneligliptin indicated that teneligliptin was metabolized or excreted from the kidney, with metabolism and renal excretion contributing to $65.6 \%$ and $34.4 \%$, respectively, of total body clearance [24]. Teneligliptin was the most abundant radioactive component in plasma (71.1\%); the most abundant metabolite in plasma was a thiazolidine-1-oxide derivative (designated as M1, $14.7 \%$ ). The main enzymes responsible for teneligliptin metabolism are cytochrome P450 (CYP) 3A4 and flavincontaining monooxygenase 3 (FMO3), with equal contribution [33] (Fig. 2). Because of its elimination via multiple pathways, teneligliptin is considered a suitable treatment 
Table 1 Pharmacokinetic profile of teneligliptin in healthy Japanese subjects [24, 31]

\begin{tabular}{|c|c|c|c|c|c|c|c|}
\hline Category & Day & Dose (mg/day) & $n$ & $t_{\max }(\mathrm{h})^{\mathrm{a}}$ & $C_{\max }(\mathrm{ng} / \mathrm{mL})^{\mathrm{b}}$ & $\mathrm{AUC}_{\infty}(\mathrm{ng} \cdot \mathrm{h} / \mathrm{mL})^{\mathrm{b}}$ & $t_{1 / 2}(\mathrm{~h})^{\mathrm{b}}$ \\
\hline \multicolumn{8}{|c|}{ Single-dose } \\
\hline & 1 & 20 & 6 & $1.8(1.0,2.0)$ & $187.20(44.70)$ & $2028.9(459.5)$ & $24.2(5.0)$ \\
\hline & 1 & 40 & 6 & $1.0(0.5,3.0)$ & $382.40(89.83)$ & $3705.1(787.0)$ & $20.8(3.2)$ \\
\hline \multicolumn{8}{|c|}{ Multiple-dose } \\
\hline & 1 & 20 & 7 & $1.0(0.4,2.0)$ & $160.60(47.26)$ & $1627.9(427.8)$ & $25.8(4.9)$ \\
\hline & 7 & 20 & 7 & $1.0(1.0,1.0)$ & $220.14(59.86)$ & $2641.4(594.7)$ & $30.2(6.9)$ \\
\hline
\end{tabular}

$A U C_{\infty}$ area under the plasma concentration-time curve from time zero to infinity, $C_{\max }$ maximal plasma concentration, $t_{\max }$ time to reach $C_{\max }, t_{1 / 2}$ elimination half-life

${ }^{\mathrm{a}}$ Median (minimum, maximum)

${ }^{\mathrm{b}}$ Mean (standard deviation)

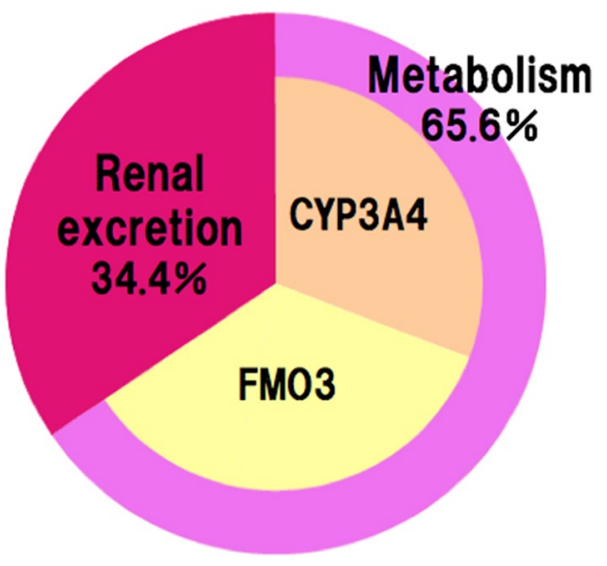

Fig. 2 Multiple elimination pathways of teneligliptin. Teneligliptin is metabolized by CYP3A4 and FMO3, or excreted from the kidney as unchanged form. $C Y P$ cytochrome $\mathrm{P} 450$, FMO3 flavin-containing monooxygenase 3

option for patients with hepatic or renal impairment, and is considered to have a low potential for drug-drug interactions, as described below.

\subsection{Special Subject Populations}

The pharmacokinetic properties of teneligliptin in special populations were evaluated in Caucasian subjects.

\subsubsection{Subjects with Renal Impairment/Hepatic Impairment}

The pharmacokinetic properties of teneligliptin have been evaluated in subjects with normal renal function and renal impairment (Table 2) [34]. Patients were assigned to one of four groups based on their renal function [mild, moderate, severe renal impairment, as assessed using Cockcroft-Gault estimates of creatinine clearance [35], or end-stage renal disease (ESRD)] and two groups of matched healthy subjects. In individuals with mild, moderate, or severe renal impairment, or ESRD, who received a single dose of teneligliptin $20 \mathrm{mg}$, no greater than a twofold increase in teneligliptin AUC from time zero to infinity $\left(\mathrm{AUC}_{\infty}\right)$ relative to healthy controls was observed. Changes in $C_{\max }$ and $t_{1 / 2}$ were unremarkable. Dialysis is not expected to affect the pharmacokinetic profile of teneligliptin; the removal of teneligliptin after dialysis was $15.6 \%$ [34].

The pharmacokinetics of teneligliptin were compared in three groups of eight subjects who were categorized according to their degree of hepatic impairment [two groups with chronic (> 6 months), stable, mild (Child-Pugh score 5-6), or moderate (Child-Pugh score 7-9) hepatic impairment, and one group of matched healthy subjects] (Table 2) [36]. Hepatic impairment was associated with a mild increase in $C_{\max }$ and overall exposure ( $\mathrm{AUC}_{\infty}$ ) relative to healthy controls; however, no greater than a twofold increase was observed [36]. Collectively, pharmacokinetic changes were unremarkable; thus, no dose adjustment of teneligliptin is required in patients with renal or hepatic impairment.

\subsubsection{Elderly Subjects}

In a placebo-controlled, randomized, double-blind, parallel-group comparative study in 40 healthy adult patients [ 21 non-elderly (aged $\geq 45$ and $<65$ years) and 19 elderly (aged $\geq 65$ and $\leq 75$ years) individuals] who received a single dose of placebo or teneligliptin 20 or $80 \mathrm{mg}$, the ratio (elderly/non-elderly) of the geometric least square (LS) means of $C_{\max }$, AUC from time zero to time $t\left(\mathrm{AUC}_{t}\right)$, and $t_{1 / 2}$ of plasma teneligliptin was approximately 1.0 across all parameters, demonstrating a similar pharmacokinetic profile between elderly and non-elderly individuals. The results of teneligliptin $20 \mathrm{mg}$ administration are shown in Table 2 [31].

\subsection{Drug-Drug Interactions}

The results from drug-drug interaction studies are presented in Table 3. Teneligliptin is metabolized by CYP3A4 and is a 
Table 2 Pharmacokinetic profile of teneligliptin in special populations

\begin{tabular}{|c|c|c|c|c|c|c|c|c|}
\hline & \multirow{2}{*}{$\begin{array}{l}\text { Dose } \\
\text { (mg/ } \\
\text { day) }\end{array}$} & \multirow[t]{2}{*}{$n$} & \multirow[t]{2}{*}{$C_{\max }(\mathrm{ng} / \mathrm{mL})^{\mathrm{a}}$} & \multirow[t]{2}{*}{$\mathrm{AUC}_{\infty}(\mathrm{ng} \cdot \mathrm{h} / \mathrm{mL})^{\mathrm{a}}$} & \multirow[t]{2}{*}{$t_{1 / 2}(\mathrm{~h})^{\mathrm{a}}$} & \multicolumn{3}{|c|}{ Ratio to normal subjects $(90 \% \mathrm{CI})^{\mathrm{b}}$} \\
\hline & & & & & & $C_{\max }$ & $\mathrm{AUC}_{\infty}$ & $t_{1 / 2}$ \\
\hline \multicolumn{9}{|c|}{ Renal impairment [34] } \\
\hline Normal & 20 & 8 & $176.50(38.42)$ & $1772.7(657.3)$ & $26.1(5.0)$ & & & \\
\hline Mild & 20 & 8 & $207.96(53.31)$ & $2234.2(278.6)$ & $27.7(7.9)$ & $1.08(0.86,1.35)$ & $1.25(1.01,1.54)$ & $1.00(0.76,1.31)$ \\
\hline Moderate & 20 & 8 & $203.63(42.33)$ & $3090.3(868.6)$ & $36.0(11.0)$ & $1.12(0.89,1.40)$ & $1.68(1.36,2.07)$ & $1.36(1.04,1.79)$ \\
\hline Severe & 20 & 8 & $191.63(49.07)$ & $2833.3(652.3)$ & $29.8(11.0)$ & $1.04(0.82,1.32)$ & $1.49(1.19,1.86)$ & $1.02(0.77,1.37)$ \\
\hline \multicolumn{9}{|c|}{ Renal impairment with ESRD [34] } \\
\hline Normal & 20 & 8 & $195.75(43.28)$ & $1843.1(450.0)$ & $18.3(5.7)$ & & & \\
\hline Pre-dialysis & 20 & 8 & $164.45(78.85)$ & $2162.5(488.1)$ & $22.7(7.7)$ & $0.85(0.64,1.13)$ & $1.17(0.94,1.47)$ & $1.19(0.89,1.59)$ \\
\hline Post-dialysis & 20 & 8 & $219.00(118.91)$ & $2472.9(599.7)$ & $23.6(5.8)$ & $1.10(0.82,1.46)$ & $1.32(1.06,1.65)$ & $1.31(0.98,1.75)$ \\
\hline \multicolumn{9}{|c|}{ Hepatic impairment [36] } \\
\hline Normal & 20 & 8 & $185.88(84.65)$ & $1548.8(209.1)$ & $24.8(6.4)$ & & & \\
\hline Mild & 20 & 8 & $229.25(86.16)$ & $2207.9(790.0)$ & $27.9(7.1)$ & $1.25(0.97,1.62)$ & $1.46(1.22,1.74)$ & $1.22(0.94,1.57)$ \\
\hline Moderate & 20 & 8 & $247.63(112.95)$ & $2418.9(505.8)$ & $30.9(6.6)$ & $1.38(1.07,1.78)$ & $1.59(1.33,1.90)$ & $1.38(1.07,1.78)$ \\
\hline \multicolumn{9}{|c|}{ Age (years) [31] } \\
\hline$\geq 45$ to $<65$ & 20 & 12 & $143.6^{\mathrm{c}}$ & $1637.6^{\mathrm{c}}$ & $33.8^{\mathrm{c}}$ & & & \\
\hline$\geq 65$ to $\leq 75$ & 20 & 12 & $142.7^{\mathrm{c}}$ & $1502.8^{c}$ & $32.1^{\mathrm{c}}$ & $1.01(0.87,1.16)$ & $1.09(0.98,1.22)$ & $1.05(0.91,1.22)$ \\
\hline
\end{tabular}

$A U C_{\infty}$ area under the plasma concentration-time curve from time zero to infinity, $C_{\max }$ maximal plasma concentration, $E S R D$ end-stage renal disease, $t_{1 / 2}$ elimination half-life, $C I$ confidence interval

${ }^{a}$ Mean (standard deviation)

${ }^{b}$ Results are reported as ratios of geometric means and the respective $90 \%$ CIs

${ }^{c}$ Data are expressed as least square means as these were the only data available

weak substrate of P-glycoprotein. The effects of the CYP3A4 and P-glycoprotein inhibitor ketoconazole on teneligliptin pharmacokinetics in healthy adults were investigated in an open-label, fixed-sequence study conducted in 16 healthy volunteers (14 of whom were included in the pharmacokinetic analysis set) in Germany [37]. Exposure to teneligliptin, when administered in combination with ketoconazole, was less than twice the exposure to teneligliptin alone, which suggests that drugs and foods that inhibit CYP3A4 are unlikely to markedly increase exposure to teneligliptin [37]. No clinically relevant drug-drug interactions were observed when teneligliptin was coadministered with metformin, canagliflozin, glimepiride, or pioglitazone in healthy volunteers; therefore, no dose adjustment of teneligliptin is required when it is coadministered with these drugs. Furthermore, teneligliptin did not affect the pharmacokinetic properties of metformin, canagliflozin, glimepiride, or pioglitazone $[31,38,39]$.

\section{Pharmacokinetic/Pharmacodynamic Data in Type 2 Diabetes Mellitus}

A pharmacokinetic/pharmacodynamic (PK/PD) study was conducted in Japanese patients with T2DM [40]. Ninetynine patients were administered teneligliptin 10 or $20 \mathrm{mg}$ or placebo before breakfast for 4 weeks in a randomized, double-blind, placebo-controlled, parallel-group study. Both teneligliptin-treated groups showed significantly decreased PPG after each meal, 24-h mean glucose, and fasting plasma glucose (FPG) values compared with the placebo group. The differences between the teneligliptin $20 \mathrm{mg}$ and placebo groups in changing 2-h PPG [LS means \pm standard error (SE)] after each meal were $-38.1 \pm 7.8,-28.6 \pm 9.2$, and $-36.1 \pm 7.5 \mathrm{mg} / \mathrm{dl}$ at breakfast, lunch, and dinner, respectively ( $p<0.001, p<0.01$, and $p<0.001$, respectively). Both doses of teneligliptin increased postprandial plasma active GLP-1 concentrations compared with placebo after each meal, and DPP-4 inhibition was sustained over $24 \mathrm{~h}$, with slightly stronger inhibition observed with the $20 \mathrm{mg}$ dose. The pharmacokinetic profile was similar to that observed in healthy subjects. These PK/PD data provided the evidence required to support the dosing of teneligliptin $20 \mathrm{mg}$ once daily [40].

\section{Clinical Studies in Japan}

\subsection{Monotherapy}

Efficacy data from relevant clinical trials are summarized in Table 4. The efficacy of teneligliptin was confirmed in 
Table 3 Drug-drug interactions: effect on teneligliptin pharmacokinetics

\begin{tabular}{|c|c|c|c|c|c|c|c|c|}
\hline \multirow[t]{2}{*}{ Combination } & \multirow{2}{*}{$\begin{array}{l}\text { Dose } \\
\text { (mg/day) }\end{array}$} & \multirow[t]{2}{*}{$n$} & \multirow[t]{2}{*}{$C_{\max }(\mathrm{ng} / \mathrm{mL})^{\mathrm{a}}$} & \multirow[t]{2}{*}{$\mathrm{AUC}_{\infty}(\mathrm{ng} \cdot \mathrm{h} / \mathrm{mL})^{\mathrm{a}}$} & \multirow[t]{2}{*}{$t_{1 / 2}(\mathrm{~h})^{\mathrm{a}}$} & \multicolumn{3}{|c|}{ Ratio to teneligliptin alone $(90 \% \mathrm{CI})^{\mathrm{b}}$} \\
\hline & & & & & & $C_{\max }$ & $\mathrm{AUC}_{\infty}$ & $t_{1 / 2}$ \\
\hline \multicolumn{9}{|l|}{ Ketoconazole [37] } \\
\hline Teneligliptin alone & 20 & 14 & $222.8(43.5)$ & $2039.6(265.3)$ & $20.7(4.2)$ & & & \\
\hline $\begin{array}{l}\text { Teneligliptin + keto- } \\
\text { conazole }\end{array}$ & 20 & 14 & $308.8(77.6)$ & $3064.1(523.5)$ & $21.8(3.9)$ & $1.37(1.25,1.50)$ & $1.49(1.39,1.60)$ & $1.06(0.95,1.18)$ \\
\hline \multicolumn{9}{|l|}{ Metformin [38] } \\
\hline Teneligliptin alone & 40 & 19 & $446.3(62.7)$ & $3352.0(538.5)^{\mathrm{c}}$ & & & & \\
\hline $\begin{array}{l}\text { Teneligliptin + met- } \\
\text { formin }\end{array}$ & 40 & 19 & 405.7 (63.9) & $3477.9(459.7)^{\mathrm{c}}$ & & $0.91(0.85,0.97)$ & $1.04(1.00,1.09)$ & \\
\hline \multicolumn{9}{|l|}{ Glimepiride [31] } \\
\hline Teneligliptin alone & 40 & 16 & $545.4(169.0)$ & $3970.0(710.5)$ & $22.6(5.9)$ & & & \\
\hline $\begin{array}{l}\text { Teneligliptin + glime- } \\
\text { piride }\end{array}$ & 40 & 16 & $523.1(134.9)$ & $3663.6(604.9)$ & $24.9(5.5)$ & $0.97(0.87,1.09)$ & $0.93(0.89,0.96)$ & $1.10(0.97,1.26)$ \\
\hline \multicolumn{9}{|l|}{ Pioglitazone [31] } \\
\hline Teneligliptin alone & 40 & 16 & $503.3(151.0)$ & 3820.2 (440.6) & $24.7(5.5)$ & & & \\
\hline $\begin{array}{l}\text { Teneligliptin + piogl- } \\
\text { itazone }\end{array}$ & 40 & 16 & $549.7(109.0)$ & $3836.1(412.1)$ & $22.7(5.3)$ & $1.12(0.98,1.27)$ & $1.01(0.97,1.05)$ & $0.92(0.82,1.03)$ \\
\hline \multicolumn{9}{|l|}{ Canagliflozin [39] } \\
\hline Teneligliptin alone & 40 & 18 & $458.3(78.8)$ & $3781.2(646.3)$ & $24.0(6.5)$ & & & \\
\hline $\begin{array}{l}\text { Teneligliptin + cana- } \\
\text { gliflozin }\end{array}$ & 40 & 18 & $444.9(66.6)$ & 3699.5 (743.6) & $22.1(4.8)$ & $0.98(0.90,1.06)$ & $0.98(0.93,1.02)$ & $0.93(0.82,1.06)$ \\
\hline
\end{tabular}

$A U C_{\infty}$ area under the plasma concentration time-curve from time zero to infinity, $A U C_{24} \mathrm{AUC}$ from time zero to $24 \mathrm{~h}, C_{\max }$ maximal plasma concentration, $t_{1 / 2}$ elimination half-life, $C I$ confidence interval

${ }^{a}$ Mean (standard deviation)

${ }^{b}$ Results are reported as ratios of geometric means and the respective $90 \%$ confidence intervals

${ }^{\mathrm{c}} \mathrm{AUC}_{24}$

two randomized, double-blind, placebo-controlled, parallelgroup studies (phases II and III) in Japanese patients with T2DM inadequately controlled by diet and exercise [24, 25, 41]. In the phase II study (3000-A4), 324 patients were randomized to receive teneligliptin 10,20 , or $40 \mathrm{mg}$, or placebo, once daily before breakfast for 12 weeks [41]. The primary endpoint was the change in $\mathrm{HbA} 1 \mathrm{c}$ from baseline to week 12. A significantly greater reduction in $\mathrm{HbA} 1 \mathrm{c}$ was observed in all teneligliptin-treated groups compared with the placebo group from weeks 2 to 12 . Differences between the teneligliptin 10, 20, or $40 \mathrm{mg}$ groups and the placebo group for change in HbA1c $\{\mathrm{LS}$ mean [95\% confidence intervals (CIs) $]\}$ were $-0.9 \%(-1.0,-0.7),-0.9 \%(-1.1,-0.7)$, and $-1.0 \%(-1.2,-0.9)$, respectively (all $p<0.001$; baseline $\mathrm{HbA} 1 \mathrm{c}$ values in the placebo, teneligliptin 10, 20, and $40 \mathrm{mg}$ groups were $8.0 \%, 7.9 \%, 7.8 \%$, and $7.7 \%$, respectively). FPG and PPG were also significantly improved at week 12 [41]. The phase III study (3000-A5) [24, 25] sought to confirm the efficacy and safety of once daily, oral teneligliptin. Patients were randomized to teneligliptin $20 \mathrm{mg}$ or placebo in a 12-week, double-blind phase. The difference [LS mean (95\% $\mathrm{CI})]$ between the teneligliptin and placebo groups for change in $\mathrm{HbA1c}$ (primary endpoint) was $-0.79 \%(-0.94,-0.64)$. FPG and 2-h PPG were also improved significantly at week 12 [24, 25]. The incidence of AEs and serious AEs did not differ significantly between the teneligliptin and placebo groups in both studies (Table 5a). In addition, adverse drug reactions (ADRs) did not increase in the teneligliptin versus placebo groups in both studies. Hypoglycemia was the only ADR reported by $\geq 3 \%$ (3000-A4 study), being $2.5 \%(n=2)$, $0 \%(n=0), 0 \%(n=0)$, and $3.7 \%(n=3)$ in the placebo and teneligliptin 10, 20, and $40 \mathrm{mg}$ groups, respectively.

\subsection{Combination Therapy/Long-Term Therapy}

In phase III studies, the efficacy and safety of teneligliptin $20 \mathrm{mg}$ in combination with a sulfonylurea (glimepiride; 3000-A6) [42] or pioglitazone (3000-A7) [43] were evaluated in randomized, double-blind, placebo-controlled, parallel-group studies (12 weeks); thereafter, all patients received teneligliptin once daily for a 40 -week period. The phase IV study investigating teneligliptin in combination with insulin (3000-A15) was conducted in a similar manner, except that the double-blind period was 16 weeks followed 


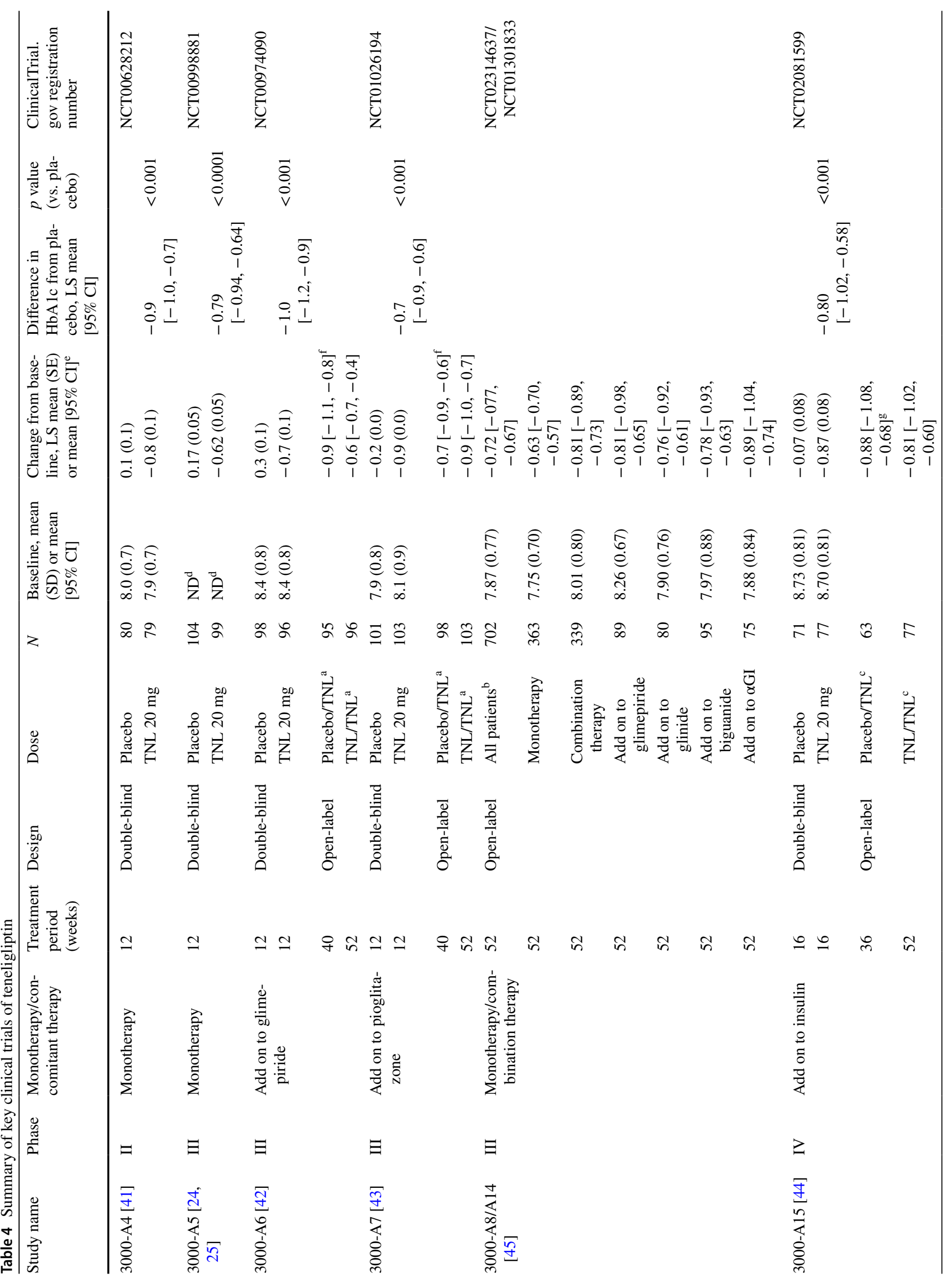




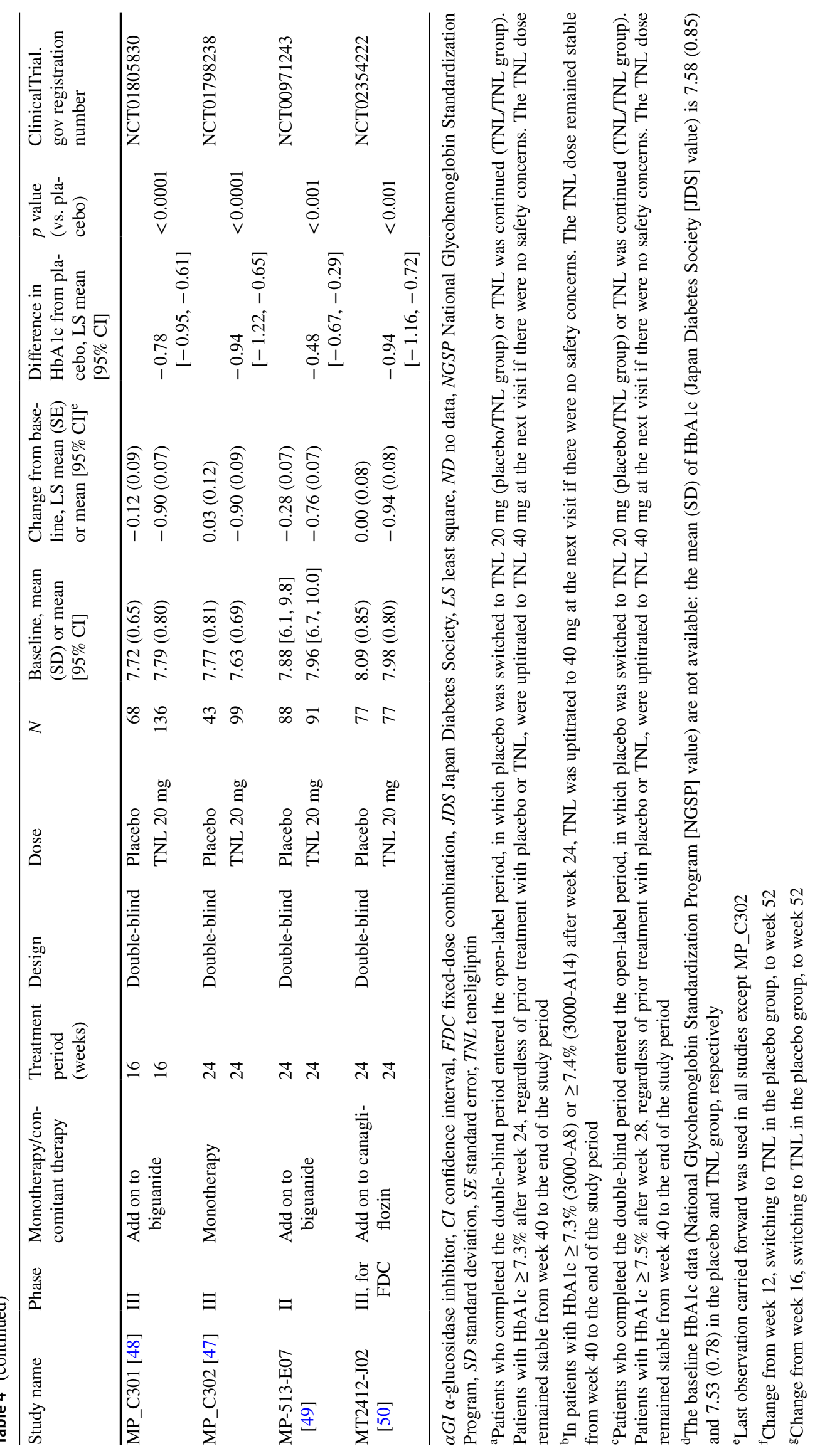


by a 36-week open-label period [44]. Patients with HbA1c $\geq 7.3 \%$ after week 24 (3000-A6, A7) [42, 43] or $\geq 7.5 \%$ after week 28 (3000-A15) [44] were uptitrated to teneligliptin $40 \mathrm{mg}$ at the next visit if there were no safety concerns. Teneligliptin as an add-on therapy to these drugs produced greater HbA1c-lowering activity than placebo, with sustained glucose-lowering effects maintained throughout the studies (up to 52 weeks). The safety profile did not differ between the placebo and teneligliptin groups, although hypoglycemia was somewhat higher when teneligliptin was administered with insulin (Table 5a).

Two long-term, open-label studies were performed in Japanese T2DM patients. The first was a long-term study of teneligliptin, both as monotherapy and in combination with glimepiride (3000-A8), and the second was a long-term study of teneligliptin, both as monotherapy and in combination with a glinide, biguanide, or $\alpha$-glucosidase inhibitor
(3000-A14). A post hoc pooled analysis using data from two phase III clinical studies involving 702 Japanese patients (3000-A8/A14) was performed [45]. The long-term use of teneligliptin as monotherapy or combination therapy significantly improved hyperglycemia in Japanese patients with T2DM, with glucose-lowering effects maintained over 52 weeks (Table 4). No change or a slight increase in bodyweight at the end of 52 weeks was observed.

As for long-term safety, the incidence of hypoglycemia was higher when teneligliptin was used in combination with sulfonylurea or insulin (10.7\% and $20.0 \%$, respectively) compared with teneligliptin monotherapy or in other combination therapies (1.1-5.0\%) [42-45]. Overall, the longterm treatment of teneligliptin was well tolerated (Table $5 b$ ).

In a post hoc pooled analysis of two 52-week, open-label, phase III clinical trials (3000-A8/A14) that examined the treatment response when teneligliptin dose was increased

Table 5 Summary of key clinical trial results: teneligliptin safety

\begin{tabular}{|c|c|c|c|c|c|c|c|c|c|c|c|c|}
\hline \multirow[t]{3}{*}{ Study type } & \multirow{2}{*}{\multicolumn{2}{|c|}{$\begin{array}{l}\text { Phase II (mono- } \\
\text { therapy) } \\
\frac{3000-\mathrm{A} 4[41][n(\%)]}{}\end{array}$}} & \multirow{2}{*}{\multicolumn{2}{|c|}{$\begin{array}{l}\text { Phase III (mono- } \\
\text { therapy) } \\
3000-\mathrm{A} 5[24][n(\%)]\end{array}$}} & \multicolumn{6}{|c|}{ Phase III (combination therapy) } & \multirow{2}{*}{\multicolumn{2}{|c|}{$\begin{array}{l}\text { Phase IV (combination } \\
\text { therapy) } \\
3000-\mathrm{A} 15[44][n(\%)]\end{array}$}} \\
\hline & & & & & \multicolumn{4}{|c|}{$3000-\mathrm{A} 6[42][n(\%)]$} & \multicolumn{2}{|c|}{$3000-\mathrm{A} 7[43][n(\%)]$} & & \\
\hline & Placebo & TNL & Placebo & TNL & SU & & $\mathrm{SU}+\mathrm{TN}$ & & PIO & $\mathrm{PIO}+\mathrm{TNL}$ & Insulin & Insulin + TNL \\
\hline \multicolumn{13}{|c|}{ (a) Double-blind trials } \\
\hline$N$ & 80 & 79 & 104 & 99 & 98 & & 96 & & 101 & 103 & 71 & 77 \\
\hline $\mathrm{AE}$ & $44(55.0)$ & $40(50.6)$ & $66(63.5)$ & $62(62.6)$ & $61(6$ & 2.2) & $62(64.6)$ & & $47(46.5)$ & $63(61.2)$ & $38(53.5)$ & $34(44.2)$ \\
\hline ADR & $6(7.5)$ & $2(2.5)$ & $5(4.8)$ & $1(1.0)$ & $6(6$. & & $8(8.3)$ & & $2(2.0)$ & $12(11.7)$ & $5(7.0)$ & $5(6.5)$ \\
\hline SAE & $1(1.3)$ & $0(0.0)$ & $4(3.8)$ & $0(0.0)$ & $2(2$. & & $0(0.0)$ & & $1(1.0)$ & $4(3.9)$ & $2(2.8)$ & $1(1.3)$ \\
\hline $\begin{array}{l}\text { Discontinued } \\
\text { because of } \\
\text { AE }\end{array}$ & $2(2.5)$ & $1(1.3)$ & $2(1.9)$ & $2(2.0)$ & $2(2$. & & $1(1.0)$ & & $2(2.0)$ & $1(1.0)$ & $4(5.6)$ & $0(0.0)$ \\
\hline Hypoglycemia & $3(3.8)$ & $1(1.3)$ & $1(1.0)$ & $1(1.0)$ & $3(3$. & & $2(2.1)$ & & $0(0.0)$ & $2(1.9)$ & $5(7.0)$ & $9(11.7)$ \\
\hline \multirow[t]{3}{*}{ Study type } & \multicolumn{2}{|c|}{$\begin{array}{l}\text { Phase III (mono- } \\
\text { therapy) }\end{array}$} & \multicolumn{10}{|c|}{ Phase III (combination therapy) } \\
\hline & \multicolumn{2}{|c|}{$\begin{array}{l}\text { 3000-A8/A14 [45] } \\
{[n(\%)]}\end{array}$} & \multicolumn{5}{|c|}{ 3000-A8/A14 [45] [n(\%)] } & \multicolumn{2}{|c|}{$\begin{array}{l}3000-\mathrm{A} 6[42] \\
{[n(\%)]}\end{array}$} & \multicolumn{2}{|c|}{$\begin{array}{l}3000-\mathrm{A} 7, \mathrm{~A}^{\mathrm{a}} \\
{[43,45][n(\%)]}\end{array}$} & $\begin{array}{l}3000-\mathrm{A} 15[44] \\
{[n(\%)]}\end{array}$ \\
\hline & \multicolumn{2}{|l|}{ TNL } & $\mathrm{GLI}+\mathrm{TNL}$ & \multicolumn{2}{|c|}{$\mathrm{BG}+\mathrm{TNL}$} & \multicolumn{2}{|c|}{$\alpha \mathrm{GI}+\mathrm{TNL}$} & $\mathrm{PIO}$ & $+\mathrm{TNL}$ & \multicolumn{2}{|c|}{$\mathrm{SU}+\mathrm{TNL}$} & Insulin + TNL \\
\hline \multicolumn{13}{|c|}{ (b) Long-term trials } \\
\hline$N$ & \multicolumn{2}{|l|}{363} & 80 & \multicolumn{2}{|l|}{95} & \multicolumn{2}{|l|}{75} & 201 & & \multicolumn{2}{|l|}{280} & 140 \\
\hline $\mathrm{AE}$ & \multicolumn{2}{|l|}{$320(88.2)$} & $72(90.0)$ & \multicolumn{2}{|c|}{$82(86.3)$} & \multicolumn{2}{|c|}{$60(80.0)$} & 178 & $(88.6)$ & \multicolumn{2}{|c|}{$266(95.0)$} & $102(72.9)$ \\
\hline ADR & \multicolumn{2}{|l|}{$31(8.5)$} & $10(12.5)$ & \multicolumn{2}{|c|}{$7(7.4)$} & \multicolumn{2}{|c|}{$5(6.7)$} & 23( & (11.4) & \multicolumn{2}{|c|}{$53(18.9)$} & $23(16.4)$ \\
\hline SAE & $20(5.5)$ & & $3(3.8)$ & $6(6.3)$ & & $6(8$ & & 14( & (7.0) & $16(5.7)$ & & $10(7.1)$ \\
\hline $\begin{array}{l}\text { Discontinued } \\
\text { because of } \\
\text { AE }\end{array}$ & $11(3.0)$ & & $5(6.3)$ & $5(5.3)$ & & $5(6$ & & $9(4$ & 4.5) & $19(6.8)$ & & $1(0.7)$ \\
\hline Hypoglycemia & $9(2.5)$ & & $4(5.0)$ & $1(1.1)$ & & $1(1$ & & $3(1$ & 1.5) & $30(10.7$ & & $28(20.0)$ \\
\hline
\end{tabular}

Medical Dictionary for Regulatory Activities/Japanese (MedDRA/J), version 11.1, 13.0, 13.1, and 15.0

$A D R$ adverse drug reaction, $A E$ adverse event, $\alpha G I \alpha$-glucosidase inhibitor, $B G$ biguanide, $G L I$ glinide, $n$ number of patients, $P I O$ pioglitazone, $S U$ sulfonylurea, $S A E$ serious adverse event, $T N L$ teneligliptin

${ }^{\text {a }}$ Pooled analysis using data from the 3000 -A7 and A8 studies 
from 20 to $40 \mathrm{mg}$ at week $28(n=204)$, no increasing trends in the incidences of AEs or hypoglycemia were observed (weeks 28-52 vs. weeks 0-28). Although the incidence of serious AEs was elevated with higher doses of teneligliptin, none of these AEs were related to the study drug. While the HbA1c reduction in the dose-increased population was low (approximately $-0.1 \%$ ), $52.9 \%$ of patients showed a response to the teneligliptin dose increase (HbA1c change less than or equal to $-0.1 \%$ ). Therefore, a dose increase to $40 \mathrm{mg}$ may be an important therapeutic option for some patients [46].

In a subgroup analysis of a 52-week, pooled study (3000A8/A14) stratified by age ( $<65$ and $\geq 65$ years), there were no differences in efficacy and safety profiles between subgroups. Moreover, no elevation in the incidence of hypoglycemia was observed in elderly patients treated with teneligliptin compared with non-elderly patients [45]. Similarly, when teneligliptin was used as an adjunct to insulin (3000A15), there was no trend towards a higher incidence of hypoglycemia in patients aged $<65$ years versus those aged $\geq 65$ years [44].

\section{Data from Non-Japanese Studies}

The 24-week efficacy of teneligliptin was assessed in Korean patients with T2DM inadequately controlled with diet and exercise (MP_C302) [47]. Patients were randomized to receive placebo or teneligliptin $20 \mathrm{mg}$ once daily for 24 weeks. At week 24, the difference in change in HbA1c from baseline [LS mean $(95 \% \mathrm{CI})]$ between the teneligliptin and placebo groups was $-0.94 \%(-1.22,-0.65)$ $(p<0.0001)$. In addition, two other studies assessed the efficacy and safety of teneligliptin plus metformin in the treatment of T2DM in Korean (MP_C301) and European patients (MP-513-E07) [48, 49]. This combination has complementary effects and the potential to provide better blood glucose control than metformin alone. Teneligliptin plus metformin was well tolerated and significantly reduced HbA1c and FPG versus placebo in both studies.

\section{Development of a Fixed-Dose Combination Drug}

The efficacy and safety of teneligliptin as add-on therapy to canagliflozin was evaluated in patients with T2DM who had inadequate glycemic control with canagliflozin monotherapy (MT2412-J02). Patients were randomized to receive teneligliptin $20 \mathrm{mg}(n=77)$ or placebo $(n=77)$ once daily. Teneligliptin as an add-on therapy to canagliflozin provided a greater HbA1c-lowering effect than placebo [betweengroup difference $-0.94 \%(-1.16,-0.72) ; p<0.001]$ by week 24 [50]. Similar results were reported when canagliflozin was administered as an add-on therapy to teneligliptin over 24 weeks in a double-blind, placebo-controlled study [difference versus placebo in the change from baseline $-0.88 \%(-1.15,-0.60) ; p<0.001$ ] [51] or 52 weeks in a long-term, open-label study [difference versus baseline $-0.99 \%(-1.12,-0.85)$ ] [52]. No new safety concerns were identified during the studies. A drug-drug interaction was not observed, as described in Sect. 4.4. Results from these trials led the Japanese PMDA, from July 2017, to approve the dual therapy (teneligliptin/canagliflozin) as a FDC for clinical use in T2DM. This was the first approval of a DPP-4 inhibitor/SGLT-2 inhibitor FDC tablet in Japan.

\section{Postmarketing Surveillance}

Although the efficacy and safety profiles of teneligliptin were characterized in clinical trials, these studies were relatively short-term (12-52 weeks). Therefore, to assess longterm safety and efficacy, the 3-year, postmarketing surveillance (PMS) RUBY (exploRing the long-term efficacy and safety including cardiovascUlar events in patients with type 2 diaBetes treated bY teneligliptin in the real-world; JapicCTI-153047) is being performed in more than 10,000 Japanese patients. Interim results (data cut-off date 28 June 2017) are shown in Table 6 [53]. Safety data were available from 10,532 Japanese T2DM patients (6338 males/4194 females) with a median administration period of 731 days. Overall, ADRs and serious ADRs were reported in 364 (3.46\%) and 91 patients $(0.86 \%)$, respectively, and hypoglycemia, constipation, and hepatic function abnormal were the most common ADRs. Hypoglycemia (0.32\%) and constipation $(0.27 \%)$ were the most common ADRs reported in pooled data from clinical trials ( $2.6 \%$ and $0.9 \%$, respectively); however, hepatic function abnormal, albeit mild in severity, was reported more frequently in this survey $(0.24 \%)$ than in the pooled analysis $(0.1 \%)$ [53]. Teneligliptin, administered as monotherapy or as combination therapy for up to 2 years, reduced $\mathrm{HbA} 1 \mathrm{c}$ from 3 months of treatment, with sustained glucose-lowering effects observed over 2 years. No change in mean bodyweight was observed. A subgroup analysis was also performed across three age groups $(<65$ years; $65-<75$ years; and $\geq 75$ years); efficacy and safety profiles did not differ markedly among the three age groups (Table 6).

A further interim subgroup analysis was performed on data obtained from patient case reports in the RUBY surveillance to verify the long-term safety and efficacy of teneligliptin in Japanese patients with T2DM and impaired renal function [54]. At the start of teneligliptin treatment, patients were classified into G1-G5 stages of chronic kidney disease (CKD) according to estimated glomerular filtration rate 
Table 6 Safety and efficacy profile of teneligliptin in the RUBY postmarketing surveillance program [53]

\begin{tabular}{|c|c|c|c|c|}
\hline & \multicolumn{4}{|l|}{ Categories } \\
\hline & All patients $[n(\%)]$ & $<65$ years $[n(\%)]$ & 65 to $<75$ years $[n(\%)]$ & $\geq 75$ years $[n(\%)]$ \\
\hline \multicolumn{5}{|l|}{ Safety (safety analysis set) } \\
\hline \multicolumn{5}{|l|}{ ADRs (serious + non-serious) } \\
\hline No. of patients & 10,532 & 4527 & 3320 & 2685 \\
\hline ADRs & $364(3.46)$ & $135(2.98)$ & $133(4.01)$ & $96(3.58)$ \\
\hline All hypoglycemia ${ }^{a}$ & $34(0.32)$ & $9(0.20)$ & $18(0.54)$ & $7(0.26)$ \\
\hline Hypoglycemia & $25(0.24)$ & $5(0.11)$ & $15(0.45)$ & $5(0.19)$ \\
\hline Blood glucose decreased & $8(0.08)$ & $4(0.09)$ & $3(0.09)$ & $1(0.04)$ \\
\hline Hypoglycemic unconsciousness & $1(0.01)$ & $0(0.00)$ & $0(0.00)$ & $1(0.04)$ \\
\hline Constipation & $28(0.27)$ & $10(0.22)$ & $12(0.36)$ & $6(0.22)$ \\
\hline Hepatic function abnormal & $25(0.24)$ & $15(0.33)$ & $4(0.12)$ & $6(0.22)$ \\
\hline \multicolumn{5}{|l|}{ Serious ADRs } \\
\hline Serious ADRs & $91(0.86)$ & $22(0.49)$ & $34(1.02)$ & $35(1.30)$ \\
\hline All hypoglycemia ${ }^{a}$ & $9(0.09)$ & $2(0.04)$ & $4(0.12)$ & $3(0.11)$ \\
\hline Hypoglycemia & $7(0.07)$ & $2(0.04)$ & $3(0.09)$ & $2(0.07)$ \\
\hline Blood glucose decreased & $1(0.01)$ & $0(0.00)$ & $1(0.03)$ & $0(0.00)$ \\
\hline Hypoglycemic unconsciousness & $1(0.01)$ & $0(0.00)$ & $0(0.00)$ & $1(0.04)$ \\
\hline \multicolumn{5}{|l|}{ Efficacy (efficacy analysis set) } \\
\hline \multicolumn{5}{|l|}{$\operatorname{HbA1c}(\%)$} \\
\hline No. of patients at the start & 9296 & 3995 & 2977 & 2324 \\
\hline No. of patients at 2 years & 4549 & 1966 & 1498 & 1085 \\
\hline $\begin{array}{l}\text { Change from baseline to } 2 \text { years } \\
\text { [mean (SD)] }\end{array}$ & $-0.75(1.36)$ & & & \\
\hline LS mean $(\mathrm{SE})$ & & $-0.72(0.02)$ & $-0.76(0.02)$ & $-0.77(0.03)$ \\
\hline
\end{tabular}

Medical Dictionary for Regulatory Activities/Japanese (MedDRA/J), version 20.0

$A D R s$ adverse drug reactions, $L S$ least square, $S E$ standard error, $S D$ standard deviation

a 'All hypoglycemia' included hypoglycemia, blood glucose decreased, and hypoglycemic unconsciousness

(eGFR). Patients on dialysis were also included. The incidence of ADRs ranged from 2.98-6.98\% across subgroups. The difference in ADR incidence is possibly attributable to bias associated with the limited number of patients in each subgroup, especially the small number of patients with G4 $(n=215)$ or G5 $(n=60)$ CKD, or ESRD $(n=152)$; thus, it cannot be concluded that the incidence differs according to renal function. Irrespective of renal function levels, treatment with teneligliptin over 2 years led to improvements in glycemic control in all subgroups.

\section{Efficacy in Patients with Renal Impairment}

Because teneligliptin can be used in T2DM patients with renal impairment, including those on hemodialysis, without the need for dose adjustment, the efficacy and safety of teneligliptin in T2DM patients with CKD requiring hemodialysis has been assessed in several small observational studies [55-59]. Otsuki et al. showed that administration of teneligliptin $20 \mathrm{mg}(n=14)$ significantly reduced glycated albumin (GA) compared with controls at week $28(-3.1 \%$, $p<0.05$; baseline means of $21.9 \%$ in the control group and $21.1 \%$ in the teneligliptin group) [55]. Furthermore, Homma et al. showed that treatment with teneligliptin $(n=15)$ over 12 weeks markedly reduced FPG compared with controls $(n=10)$ [56]. Treatment with teneligliptin was well tolerated in both studies, with no episodes of hypoglycemia reported.

Wada et al. showed that 4-week teneligliptin treatment $(n=10$; patients had a GA level $\geq 18.3 \%)$ improved blood glucose AUC as assessed by continuous glucose monitoring (CGM) on both hemodialysis and non-hemodialysis days (both $p=0.004$ ) and significantly reduced GA and FPG values, without severe hypoglycemia [57]. In a randomized, crossover study in T2DM patients $(n=13)$ with CKD, Tanaka et al. showed that teneligliptin $20 \mathrm{mg}$ /day or linagliptin $5 \mathrm{mg}$ /day (administered once daily for 6 days and then switching for a further 6 days) had comparable beneficial effects on mean amplitude of glucose excursion, 24-h mean sensor glucose levels, and AUC for sensor glucose levels $\geq 180 \mathrm{mg} / \mathrm{dL}$ (AUC $\geq 180$ ), with a comparable incidence of 
hypoglycemia [58]. Finally, Yajima et al. assessed the efficacy of once-daily teneligliptin $20 \mathrm{mg}$, when coadministered with insulin in 21 T2DM patients on hemodialysis, by CGM and found that coadministration of teneligliptin and insulin significantly reduced median (interquartile range) total daily insulin dose from $18 \mathrm{U}(9-24)$ to $6 \mathrm{U}(0-14)(p<0.0001)$ and significantly reduced the incidence of asymptomatic hypoglycemia on the hemodialysis day from 38.1 to $19.0 \%$ $(p=0.049)$ [59]. Collectively, these results suggest that teneligliptin is a valuable treatment option for glycemic control in patients with T2DM undergoing hemodialysis.

\section{Effects of Teneligliptin on Oxidative Stress and Endothelial Function}

Teneligliptin appears to have multifaceted effects on endothelial function, via its antioxidant capabilities, antiinflammatory properties, antiplatelet activity, and hydroxylradical $(\cdot \mathrm{OH})$ scavenging properties. Oxidative stress induced by elevated glucose levels facilitates cardiovascular endothelial damage in T2DM [8,9]. Two studies sought to verify the potential protective action of teneligliptin or teneligliptin in combination with GLP-1, in endothelial cells exposed to high glucose (HG) [60, 61]. In both studies, human umbilical vein endothelial primary cells (HUVECs) were exposed to normal glucose $(\mathrm{NG} ; 5 \mathrm{mmol} / \mathrm{L})$ or $\mathrm{HG}$ ( $25 \mathrm{mmol} / \mathrm{L}$ ) for 21 days, or to HG for 14 days followed by NG for 7 days to mimic a high-metabolic memory state (HM). The cells were continually treated with either teneligliptin $(0.1,1.0$, and $3.0 \mu \mathrm{mol} / \mathrm{L})$ or sitagliptin $(0.5 \mu \mathrm{mol} / \mathrm{L})$ [60], or with teneligliptin $(3.0 \mu \mathrm{mol} / \mathrm{L})$ [61]. Teneligliptin demonstrated antioxidant properties by reducing reactive oxygen species (ROS) levels and initiating the transcriptional cascade of antioxidant genes at the cellular level. Of note, the efficacy of teneligliptin $0.1 \mu \mathrm{mol} / \mathrm{L}$ at reducing ROS was similar to that observed with sitagliptin $0.5 \mu \mathrm{mol} / \mathrm{L}$, suggesting that teneligliptin has more potent antioxidant properties. Moreover, it enhanced proliferation and endoplasmic reticulum homeostasis, reduced apoptosis in HG conditions, and overcame the metabolic memory effect [60, 61]. GLP-1 has a vascular protective effect, which enhances the antioxidative pathway; however, hyperglycemia reduces its positive effect, a phenomenon known as 'GLP-1 endothelial resistance' [62]. The combination of teneligliptin and GLP-1 enhanced the antioxidant response of teneligliptin in HG- and HM-exposed HUVECs, which suggests that the simultaneous administration of these two drugs can counter GLP-1 endothelial resistance [61].

In addition to inducing the transcriptional cascade of antioxidant genes, teneligliptin has $\cdot \mathrm{OH}$ scavenging properties. While teneligliptin does not scavenge $\mathrm{O}_{2}^{-}$, it has been shown to scavenge $\cdot \mathrm{OH}$. This was confirmed by $\mathrm{X}$-band electron spin resonance spectroscopy using a spin trap agent to detect free radicals and estimate radical scavenging properties and, in vivo, by assessing the effect of oral teneligliptin on urinary excretion of 8-hydroxy-2'-deoxyguanosine (8-OHdG) in DPP-4-deficient diabetic rats [63]. Teneligliptin scavenged $\cdot \mathrm{OH}$ in a dose-dependent manner, changing its structure to form metabolite M1, which is also found in vivo. Teneligliptin was shown to have greater $\cdot \mathrm{OH}$ scavenging activity than glutathione, and had direct $\cdot \mathrm{OH}$ scavenging properties that are not attributable to DPP-4 inhibition because it was observed in DPP-4-deficient rats. The novel chemical structure of teneligliptin may be responsible for its .OH scavenging properties. In contrast, the DPP-4 inhibitors alogliptin and linagliptin do not exhibit $\mathrm{O}_{2}{ }^{-}$and $\cdot \mathrm{OH}$ scavenging properties [63].

Oxidative stress in perivascular adipose tissue (PVAT) contributes to systemic inflammation and may promote endothelial dysfunction and atherogenesis [64]. Oral administration of teneligliptin $(60 \mathrm{mg} / \mathrm{kg} / \mathrm{day})$ to apolipoprotein-E-deficient (ApoE KO) mice for 20 weeks reduced the expression of inflammatory molecules in PVAT, and inhibited atherosclerosis compared with vehicle. Furthermore, the administration of teneligliptin for 8 weeks ameliorated endothelium-dependent vasodilation and reduced oxidative stress, as determined by urinary 8 -OHdG excretion $(p<0.05)$, compared with vehicle [64]. Moreover, in spontaneous hypertensive rats, SHR/NDmcr-cp (cp/cp), long-term treatment with teneligliptin $(10 \mathrm{mg} / \mathrm{kg} / \mathrm{day}$ for 12 weeks) significantly attenuated endothelial dysfunction through the upregulation of endothelium-derived nitric oxide synthase mRNA [65].

A case-control study by Sagara et al. sought to elucidate the effect of teneligliptin on oxidative stress and endothelial function in Japanese patients with T2DM and CKD. Forty-five patients with T2DM and CKD who had received sitagliptin for at least 12 months were randomized to continue sitagliptin $(n=23)$ or switch to teneligliptin $(n=22)$ for 24 weeks. From baseline to 24 weeks, no significant between-group differences were noted regarding changes in $\mathrm{HbA1c}$, eGFR, and urinary albumin excretion; however, the switch to teneligliptin was associated with significantly improved values for reactive hyperemia index (RHI), a measure of endothelial function. The antioxidant activity of teneligliptin was demonstrated by decreased levels of derivatives of reactive oxygen metabolites, a novel marker of oxidative stress; this antioxidant effect was strongly linked with the improved RHI values. The suppression by teneligliptin of glucose fluctuations that induce oxidative stress, together with its antioxidant effects, may have contributed to the improvement in vascular function [66].

In a clinical study involving 103 individuals with T2DM, 47 of whom were receiving hemodialysis, teneligliptin $20 \mathrm{mg}$ administered once daily for 3 months significantly 
reduced plasma levels of soluble P-selectin, platelet-derived microparticles, and plasminogen activator inhibitor 1 compared with baseline levels, particularly in those receiving hemodialysis, and significantly increased adiponectin levels [67]. Similarly, Hashikata et al. showed that the administration of teneligliptin in T2DM patients $(n=29)$ for 3 months resulted in improvements in left ventricular function $\left(E / e^{\prime}\right.$ ratio) and endothelial function (based on reactive hyperemia peripheral arterial tonometry [RH-PAT] value), and increased serum adiponectin levels compared with baseline levels, suggesting possible cardioprotective effects [68]. The mechanism by which teneligliptin increases circulating adiponectin remains to be determined.

\section{Comparison with Other DPP-4 Inhibitors}

DPP-4 inhibitors have differing pharmacokinetic and pharmacodynamic properties that may be clinically relevant in certain patient groups. The main pharmacokinetic differences between DPP-4 inhibitors marketed in Japan are summarized in Table 7 [69-82].

The elimination half-lives of DPP-4 inhibitors are widely variable, with half-lives ranging from approximately $2 \mathrm{~h}$ to more than $100 \mathrm{~h}$ (Table 7). DPP-4 inhibitors vary in dosing regimens (once-daily, twice-daily, or once-weekly administration) according to their half-lives.

A key difference in the pharmacokinetic properties of DPP-4 inhibitors is their varied elimination routes, and this difference is related to the need for dose adjustments in T2DM patients with renal dysfunction. Whereas most DPP-4 inhibitors predominantly undergo renal excretion, linagliptin is excreted mostly unchanged in feces via biliary action [81], and teneligliptin is eliminated by hepatic metabolism mediated by CYP3A4 or FMO3, or excreted from the kidney in an unchanged form; thus, linagliptin and teneligliptin can be administered without dose adjustments in T2DM patients with renal impairment.

Teneligliptin appears to be less affected by CYP3A4 and P-glycoprotein inhibitors, because, even if such inhibition occurs, teneligliptin is still excreted via the kidneys and metabolized by FMO3. Conversely, the AUC from time zero to $24 \mathrm{~h}\left(\mathrm{AUC}_{24}\right)$ of linagliptin used in combination with ritonavir, a CYP3A4 and P-glycoprotein inhibitor, increased twofold compared with the $\mathrm{AUC}_{24}$ for linagliptin monotherapy, while the AUC during the dosing interval at steady-state $\left(\mathrm{AUC}_{\tau, \mathrm{ss}}\right)$ of linagliptin used in combination with rifampicin, a CYP3A4 and P-glycoprotein inducer, decreased by $40 \%$ [81]. These effects may be the result of the inhibition/induction of gastrointestinal P-glycoprotein $[81,83]$ and the partial inhibition/induction of CYP3A4. Therefore, linagliptin needs to be used with caution in combination with CYP inhibitors or inducers owing to possible safety risks and the potential for reduced efficacy [14, 72, 84]. Similarly, metabolism of saxagliptin is mediated via CYP3A4/5; thus, coadministration of CYP3A4/5 inhibitors and inducers can alter its pharmacokinetics, and dose reductions should be considered when saxagliptin is used in combination with CYP3A4 inhibitors $[14,74,85]$. Consideration of potential drug-drug interactions is particularly relevant for elderly patients in whom polypharmacy is common, raising the potential for diminishing treatment efficacy or increasing the risk of AEs [86].

\section{Clinical Implications}

Teneligliptin has unique pharmacokinetic and pharmacological properties. From a pharmacokinetic perspective, teneligliptin is metabolized by CYP3A4 and FMO3, or excreted from the kidney in an unchanged form. Because of its multiple elimination pathways, dose adjustment is not needed in patients with hepatic or renal impairment, and it is considered to have a low potential for drug-drug interactions. Elderly T2DM patients, especially those aged $\geq 80$ years, frequently have reduced renal function [87]. Moreover, elderly T2DM patients commonly have many medications prescribed [88]. As for FMO, a few drugs are metabolized by FMO (approximately $2 \%$ ) $[89,90]$ and the enzyme activity of FMO3 does not differ between non-elderly (30-59 years) and elderly (60-79 years) populations [91]. Therefore, FMO is an important back-up mechanism. The involvement of multiple metabolic enzymes, together with multiple elimination pathways, may make teneligliptin less susceptible to age-related pharmacokinetic changes and drug-drug interactions. In accordance with these characteristics, the pharmacokinetic profile of teneligliptin does not differ between non-elderly (45-64 years) and elderly (65-75 years) populations. Actually, the safety and efficacy profile of teneligliptin appears to be unaffected by age in clinical studies or realworld clinical data (PMS). The pharmacokinetic profile in broader populations, such as individuals aged $\geq 75$ years, has not yet been evaluated, and further research is needed to investigate the pharmacokinetic profile of teneligliptin in very elderly patients.

In addition to its DPP-4 inhibitory effect, teneligliptin has antioxidative properties, which induce the antioxidant cascade, as well as $\cdot \mathrm{OH}$ scavenging properties. Furthermore, teneligliptin has shown endothelial protective effects in several non-clinical and clinical studies. Because teneligliptin has been shown to overcome the metabolic memory effect in endothelial cells $[60,61]$, early treatment with teneligliptin may be useful for preventing diabetic complications, in addition to its glucose-lowering effect. Collectively, these unique pharmacokinetic and pharmacological properties of 


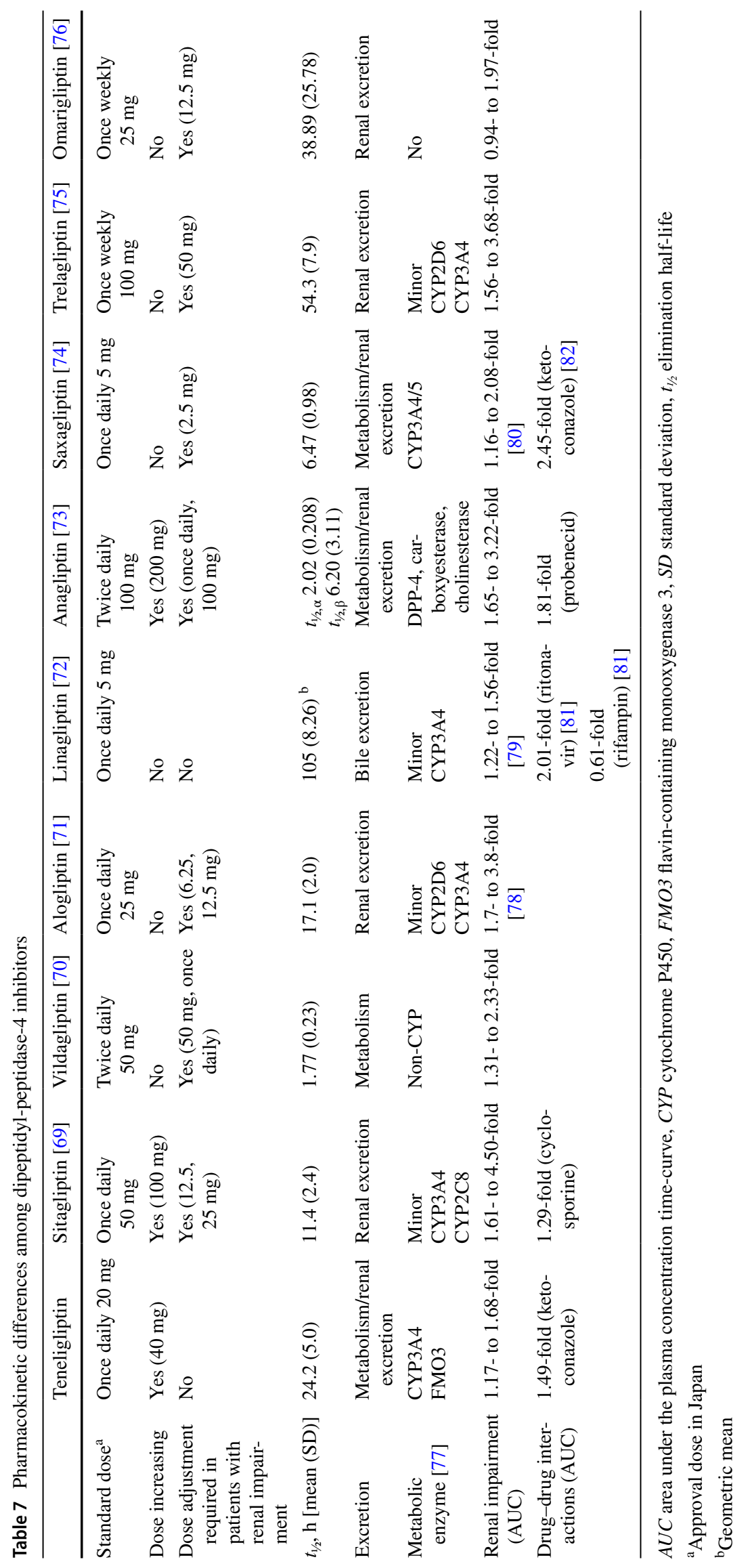


teneligliptin make it a valuable drug option for the treatment of a broad range of T2DM patients in clinical practice.

An FDC tablet of teneligliptin/canagliflozin was also approved in Japan. Owing to the differences in their mechanisms of action, teneligliptin and canagliflozin act in a complementary manner. Body weight management is important for maintaining good long-term glycemic control with DPP-4 inhibitors [92, 93], and the SGLT2 inhibitor canagliflozin reduces not only blood glucose but also body weight [94]; thus, the FDC of teneligliptin/canagliflozin also represents a useful therapeutic option for T2DM patients, with additional benefits such as adherence.

\section{Conclusions}

Teneligliptin demonstrates potent and sustained effects on glycemic control in patients with T2DM, both as a monotherapy and in combination with other antidiabetic drugs. Unlike many other DPP-4 inhibitors, the multiple elimination pathways of teneligliptin enable treatment to be administered to patients with renal or hepatic impairment without dose adjustment. Moreover, teneligliptin has pleiotropic effects, independent of glycemic control, which may lead to improved endothelial function and reduced vascular oxidative stress. These unique characteristics make teneligliptin a particularly viable consideration for a diverse range of T2DM patients, including those with renal impairment or elderly subjects.

Acknowledgements The preparation of this manuscript was supported by Mitsubishi Tanabe Pharma Corporation. The authors would like to acknowledge Emma Donadieu, MSc, and David Murdoch, of Edanz Group for medical writing support, which was supported by Mitsubishi Tanabe Pharma Corporation.

Author Contributions HI, TM, and MG conducted the literature search, contributed discussion points, and reviewed the manuscript. AC and VDN contributed discussion points relating to clinical implications, and reviewed the manuscript.

\section{Compliance with Ethical Standards}

Conflict of interest Antonio Ceriello has received research grants from Mitsubishi Tanabe Pharma Co., Astra Zeneca, Eli Lilly, and Novartis; consulting fees or honorarium from Astra Zeneca, Boehringer Ingelheim, DOC Generici, Eli Lilly, Janssen, Novo Nordisk, and OM Phar$\mathrm{ma}$; and payment for lectures, including service on speakers bureaus, from Astra Zeneca, Boehringer Ingelheim, Eli Lilly, Novartis, Novo Nordisk, Sanofi, and Takeda. Valeria De Nigris has no conflicts of interest to declare. Hiroaki Iijima, Takahiro Matsui, and Maki Gouda are employees of Mitsubishi Tanabe Pharma Corporation.

Ethical approval For this review, consent was not required.

Open Access This article is distributed under the terms of the Creative Commons Attribution-NonCommercial 4.0 International License (http://creativecommons.org/licenses/by-nc/4.0/), which permits any noncommercial use, distribution, and reproduction in any medium, provided you give appropriate credit to the original author(s) and the source, provide a link to the Creative Commons license, and indicate if changes were made.

\section{References}

1. Cho NH, Shaw JE, Karuranga S, Huang Y, da Rocha Fernandes JD, Ohlrogge AW, et al. IDF Diabetes Atlas: global estimates of diabetes prevalence for 2017 and projections for 2045. Diabetes Res Clin Pract. 2018;138:271-81.

2. International Diabetes Federation. IDF Diabetes Atlas-8th edition; 2017. http://diabetesatlas.org/resources/2017-atlas.html. Accessed 29 July 2018.

3. Charvat $\mathrm{H}$, Goto A, Goto M, Inoue M, Heianza Y, Arase Y, et al. Impact of population aging on trends in diabetes prevalence: a meta-regression analysis of 160,000 Japanese adults. J Diabetes Investig. 2015;6(5):533-42.

4. Kirkman MS, Briscoe VJ, Clark N, Florez H, Haas LB, Halter JB, et al. Diabetes in older adults. Diabetes Care. 2012;35(12):2650-64.

5. American Diabetes Association. 11. Older adults: standards of medical care in diabetes-2018. Diabetes Care. 2018;41(Suppl 1):S119-25.

6. Managing older people with type 2 diabetes: IDF Global Guidelines. International Diabetes Federation. https://www.ifa-fiv.org/ publication/health/managing-older-people-with-type-2-diabetesidf-global-guideline/. Accessed 13 Nov 2018.

7. Fowler M. Microvascular and macrovascular complications of diabetes. Clin Diabetes. 2008;26(2):77-82.

8. Roberts AC, Porter KE. Cellular and molecular mechanisms of endothelial dysfunction in diabetes. Diabetes Vasc Dis Res. 2013;10(6):472-82.

9. Kayama Y, Raaz U, Jagger A, Adam M, Schellinger IN, Sakamoto $\mathrm{M}$, et al. Diabetic cardiovascular disease induced by oxidative stress. Int J Mol Sci. 2015;16(10):25234-63.

10. Testa R, Bonfigli AR, Prattichizzo F, La Sala L, De Nigris V, Ceriello A. The, "Metabolic Memory" theory and the early treatment of hyperglycemia in prevention of diabetic complications. Nutrients. 2017;9(5):E437.

11. Cooper ME, El-Osta A, Allen TJ, Watson AMD, Thomas MC, Jandeleit-Dahm KAM. Metabolic Karma - the atherogenic legacy of diabetes: the 2017 Edwin Bierman Award Lecture. Diabetes. 2018;67(5):785-90.

12. Nauck MA, Meier JJ. Incretin hormones: their role in health and disease. Diabetes Obes Metab. 2018;20(Suppl 1):5-21.

13. Seino Y, Kuwata H, Yabe D. Incretin-based drugs for type 2 diabetes: focus on East Asian perspectives. J Diabetes Investig. 2016;7(Suppl 1):102-9.

14. Deacon CF, Lebovitz HE. Comparative review of dipeptidyl peptidase- 4 inhibitors and sulphonylureas. Diabetes Obes Metab. 2016;18(4):333-47.

15. Kim YG, Hahn S, Oh TJ, Kwak SH, Park KS, Cho YM. Differences in the glucose-lowering efficacy of dipeptidyl peptidase-4 inhibitors between Asians and non-Asians: a systematic review and meta-analysis. Diabetologia. 2013;56(4):696-708.

16. Park H, Park C, Kim Y, Rascati KL. Efficacy and safety of dipeptidyl peptidase- 4 inhibitors in type 2 diabetes: meta-analysis. Ann Pharmacother. 2012;46(11):1453-69.

17. Cho YM. Incretin physiology and pathophysiology from an Asian perspective. J Diabetes Investig. 2015;6(5):495-507. 
18. Schnell O, Ryden L, Standl E, Ceriello A, D\&CVD EASD Study Group. Updates on cardiovascular outcome trials in diabetes. Cardiovasc Diabetol. 2017;16(1):128.

19. Rosenstock J, Perkovic V, Johansen O, Cooper M, Kahn S, Marx $\mathrm{N}$, et al. Effect of linagliptin vs placebo on major cardiovascular events in adults with type 2 diabetes and high cardiovascular and renal risk: the CARMELINA randomized clinical trial. JAMA. 2019;321(1):69-79.

20. Davies MJ, D'Alessio DA, Fradkin J, Kernan WN, Mathieu C, Mingrone $\mathrm{G}$, et al. Management of hyperglycaemia in type 2 diabetes, 2018. A consensus report by the American Diabetes Association (ADA) and the European Association for the Study of Diabetes (EASD). Diabetologia. 2018;61(12):2461-98.

21. Ahuja V, Chou CH. Novel therapeutics for diabetes: uptake, usage trends, and comparative effectiveness. Curr Diabetes Rep. 2016;16(6):47.

22. Gouda M, Matsukawa M, Iijima H. Associations between eating habits and glycemic control and obesity in Japanese workers with type 2 diabetes mellitus. Diabetes Metab Syndr Obes. 2018;11:647-58.

23. Mitsubishi Tanabe Pharma Corporate Report 2017. https://www. mt-pharma.co.jp/e/ir/annual/pdf/CR_2017_en.pdf. Accessed 25 Sep 2018.

24. Evaluation and Licensing Division, Pharmaceutical and Food Safety Bureau, Ministry of Health Labour and Welfare, Japan. Report on the deliberation results: Tenelia Tablets $20 \mathrm{mg} ; 2012$. https://www.pmda.go.jp/files/000153594.pdf. Accessed 17 May 2018.

25. Goda M, Kadowaki T. Teneligliptin for the treatment of type 2 diabetes. Drugs Today (Barc). 2013;49(10):615-29.

26. Yoshida T, Akahoshi F, Sakashita H, Kitajima H, Nakamura M, Sonda $\mathrm{S}$, et al. Discovery and preclinical profile of teneligliptin (3-[(2S,4S)-4-[4-(3-methyl-1-phenyl-1H-pyrazol-5-yl)piperazin-1-yl]pyrrolidin-2-y lcarbonyl]thiazolidine): a highly potent, selective, long-lasting and orally active dipeptidyl peptidase IV inhibitor for the treatment of type 2 diabetes. Bioorg Med Chem. 2012;20(19):5705-19.

27. Nabeno M, Akahoshi F, Kishida H, Miyaguchi I, Tanaka Y, Ishii $\mathrm{S}$, et al. A comparative study of the binding modes of recently launched dipeptidyl peptidase IV inhibitors in the active site. Biochem Biophys Res Commun. 2013;434(2):191-6.

28. Fukuda-Tsuru S, Anabuki J, Abe Y, Yoshida K, Ishii S. A novel, potent, and long-lasting dipeptidyl peptidase-4 inhibitor, teneligliptin, improves postprandial hyperglycemia and dyslipidemia after single and repeated administrations. Eur J Pharmacol. 2012;696(1-3):194-202.

29. Nakamaru Y, Akahoshi F, Iijima H, Hisanaga N, Kume T. Tissue distribution of teneligliptin in rats and comparisons with data reported for other dipeptidyl peptidase-4 inhibitors. Biopharm Drug Dispos. 2016;37:142-55.

30. Mentlein R, Dipeptidyl-peptidase IV. (CD26): role in the inactivation of regulatory peptides. Regul Pept. 1999;85(1):9-24.

31. Tenelia ${ }^{\circledR}$ (teneligliptin), Common Technical Document 2012. http://www.pmda.go.jp/drugs/2012/P201200070/40031 5000_22400AMX00728_K102_2.pdf. Accessed 15 Nov 2018.

32. Nakamaru Y, Emoto C, Shimizu M, Yamazaki H. Human pharmacokinetic profiling of the dipeptidyl peptidase-IV inhibitor teneligliptin using physiologically based pharmacokinetic modeling. Biopharm Drug Dispos. 2015;36(3):148-62.

33. Nakamaru Y, Hayashi Y, Ikegawa R, Kinoshita S, Perez Madera B, Gunput D, et al. Metabolism and disposition of the dipeptidyl peptidase IV inhibitor teneligliptin in humans. Xenobiotica. 2014;44(3):242-53.

34. Halabi A, Maatouk H, Siegler KE, Faisst N, Lufft V, Klause N. Pharmacokinetics of teneligliptin in subjects with renal impairment. Clin Pharmacol Drug Dev. 2013;2(3):246-54.
35. Cockcroft DW, Gault MH. Prediction of creatinine clearance from serum creatinine. Nephron. 1976;16(1):31-41.

36. Halabi A, Maatouk H, Siegler KE, Faisst N, Hinrichsen H. Pharmacokinetics and safety of teneligliptin in subjects with hepatic impairment. Clin Pharmacol Drug Dev. 2014;3(4):290-6.

37. Nakamaru Y, Hayashi Y, Sekine M, Kinoshita S, Thompson J, Kawaguchi A, et al. Effect of ketoconazole on the pharmacokinetics of the dipeptidyl peptidase- 4 inhibitor teneligliptin: an open-label study in healthy white subjects in Germany. Clin Ther. 2014;36(5):760-9.

38. Nakamaru Y, Hayashi Y, Davies M, Jurgen Heuer H, Hisanaga N, Akimoto K. Investigation of potential pharmacokinetic interactions between teneligliptin and metformin in steady-state conditions in healthy adults. Clin Ther. 2015;37(9):2007-18.

39. Kinoshita S, Kondo K. Evaluation of pharmacokinetic and pharmacodynamic interactions of canagliflozin and teneligliptin in Japanese healthy male volunteers. Expert Opin Drug Metab Toxicol. 2015;11(1):7-14.

40. Eto T, Inoue S, Kadowaki T. Effects of once-daily teneligliptin on 24-h blood glucose control and safety in Japanese patients with type 2 diabetes mellitus: a 4-week, randomized, double-blind, placebo-controlled trial. Diabetes Obes Metab. 2012;14(11):1040-6.

41. Kadowaki T, Kondo K. Efficacy, safety and dose-response relationship of teneligliptin, a dipeptidyl peptidase-4 inhibitor, in Japanese patients with type 2 diabetes mellitus. Diabetes Obes Metab. 2013;15(9):810-8.

42. Kadowaki T, Kondo K. Efficacy and safety of teneligliptin added to glimepiride in Japanese patients with type 2 diabetes mellitus: a randomized, double-blind, placebo-controlled study with an open-label, long-term extension. Diabetes Obes Metab. 2014;16(5):418-25.

43. Kadowaki T, Kondo K. Efficacy and safety of teneligliptin in combination with pioglitazone in Japanese patients with type 2 diabetes mellitus. J Diabetes Investig. 2013;4(6):576-84.

44. Kadowaki T, Kondo K, Sasaki N, Miyayama K, Yokota S, Terata $\mathrm{R}$, et al. Efficacy and safety of teneligliptin add-on to insulin monotherapy in Japanese patients with type 2 diabetes mellitus: a 16-week, randomized, double-blind, placebo-controlled trial with an open-label period. Expert Opin Pharmacother. 2017;18(13):1291-300.

45. Kadowaki T, Marubayashi F, Yokota S, Katoh M, Iijima H. Safety and efficacy of teneligliptin in Japanese patients with type 2 diabetes mellitus: a pooled analysis of two phase III clinical studies. Expert Opin Pharmacother. 2015;16(7):971-81.

46. Kadowaki T, Sasaki K, Ishii M, Matsukawa M, Ushirogawa Y. Efficacy and safety of teneligliptin $40 \mathrm{mg}$ in type 2 diabetes: a pooled analysis of two phase III clinical studies. Diabetes Ther. 2018;9(2):623-36.

47. Hong S, Park CY, Han KA, Chung CH, Ku BJ, Jang HC, et al. Efficacy and safety of teneligliptin, a novel dipeptidyl peptidase-4 inhibitor, in Korean patients with type 2 diabetes mellitus: a 24-week multicentre, randomized, double-blind, placebo-controlled phase III trial. Diabetes Obes Metab. 2016;18(5):528-32.

48. Kim MK, Rhee EJ, Han KA, Woo AC, Lee MK, Ku BJ, et al. Efficacy and safety of teneligliptin, a dipeptidyl peptidase-4 inhibitor, combined with metformin in Korean patients with type 2 diabetes mellitus: a 16-week, randomized, double-blind, placebo-controlled phase III trial. Diabetes Obes Metab. 2015;17(3):309-12.

49. Bryson A, Jennings PE, Deak L, Paveliu FS, Lawson M. The efficacy and safety of teneligliptin added to ongoing metformin monotherapy in patients with type 2 diabetes: a randomized study with open label extension. Expert Opin Pharmacother. 2016;17(10):1309-16.

50. Kadowaki T, Inagaki N, Kondo K, Nishimura K, Kaneko G, Maruyama N, et al. Efficacy and safety of teneligliptin added to canagliflozin monotherapy in Japanese patients with type 2 
diabetes mellitus: a multicentre, randomized, double-blind, placebo-controlled, parallel-group comparative study. Diabetes Obes Metab. 2018;20(2):453-7.

51. Kadowaki T, Inagaki N, Kondo K, Nishimura K, Kaneko G, Maruyama N, et al. Efficacy and safety of canagliflozin as add-on therapy to teneligliptin in Japanese patients with type 2 diabetes mellitus: Results of a 24-week, randomized, double-blind, placebo-controlled trial. Diabetes Obes Metab. 2017;19(6):874-82.

52. Kadowaki T, Inagaki N, Kondo K, Nishimura K, Kaneko G, Maruyama N, et al. Long-term safety and efficacy of canagliflozin as add-on therapy to teneligliptin in Japanese patients with type 2 diabetes. Diabetes Obes Metab. 2018;20(1):77-84.

53. Kadowaki T, Haneda M, Ito H, Ueno M, Matsukawa M, Yamakura $\mathrm{T}$, et al. Safety and efficacy of long-term treatment with teneligliptin: Interim analysis of a post-marketing surveillance of more than 10,000 Japanese patients with type 2 diabetes mellitus. Expert Opin Pharmacother. 2018;19(2):83-91.

54. Haneda M, Kadowaki T, Ito H, Sasaki K, Hiraide S, Ishii M, et al. Safety and efficacy of teneligliptin in patients with type 2 diabetes mellitus and impaired renal function: interim report from postmarketing surveillance. Diabetes Ther. 2018;9(3):1083-97.

55. Otsuki H, Kosaka T, Nakamura K, Shimomura F, Kuwahara Y, Tsukamoto T. Safety and efficacy of teneligliptin: a novel DPP-4 inhibitor for hemodialysis patients with type 2 diabetes. Int Urol Nephrol. 2014;46(2):427-32.

56. Homma K, Yoshizawa J, Shiina Y, Ozawa H, Igarashi M, Matsuoka $\mathrm{T}$, et al. A dipeptidyl peptidase-4 inhibitor, teneligliptin, decreases plasma triglyceride-rich lipoprotein remnants in diabetic patients with chronic kidney disease undergoing hemodialysis. Drugs R D. 2017;17(3):397-402.

57. Wada N, Mori K, Nakagawa C, Sawa J, Kumeda Y, Shoji T, et al. Improved glycemic control with teneligliptin in patients with type 2 diabetes mellitus on hemodialysis: evaluation by continuous glucose monitoring. J Diabetes Complic. 2015;29(8):1310-3.

58. Tanaka K, Okada Y, Mori H, Inada Y, Suzuka K, Uriu K, et al. Efficacy of linagliptin and teneligliptin for glycemic control in type 2 diabetic patients with chronic kidney disease: assessment by continuous glucose monitoring; a pilot study. Diabetol Int. 2016;7(4):368.

59. Yajima T, Yajima K, Hayashi M, Takahashi H, Yasuda K. Efficacy and safety of teneligliptin in addition to insulin therapy in type 2 diabetes mellitus patients on hemodialysis evaluated by continuous glucose monitoring. Diabetes Res Clin Pract. 2016;122:78-83.

60. Pujadas G, De Nigris V, Prattichizzo F, La Sala L, Testa R, Ceriello A. The dipeptidyl peptidase-4 (DPP-4) inhibitor teneligliptin functions as antioxidant on human endothelial cells exposed to chronic hyperglycemia and metabolic high-glucose memory. Endocrine. 2017;56(3):509-20.

61. De Nigris V, Prattichizzo F, Mancuso E, Spiga R, Pujadas G, Ceriello A. Teneligliptin enhances the beneficial effects of GLP-1 in endothelial cells exposed to hyperglycemic conditions. Oncotarget. 2018;9(10):8898-910.

62. Ceriello A, Esposito K, Testa R, Bonfigli AR, Marra M, Giugliano D. The possible protective role of glucagon-like peptide 1 on endothelium during the meal and evidence for an "endothelial resistance" to glucagon-like peptide 1 in diabetes. Diabetes Care. 2011;34(3):697-702.

63. Kimura S, Inoguchi T, Yamasaki T, Yamato M, Ide M, Sonoda $\mathrm{N}$, et al. A novel DPP-4 inhibitor teneligliptin scavenges hydroxyl radicals: In vitro study evaluated by electron spin resonance spectroscopy and in vivo study using DPP-4 deficient rats. Metabolism. 2016;65(3):138-45.

64. Salim HM, Fukuda D, Higashikuni Y, Tanaka K, Hirata Y, Yagi $\mathrm{S}$, et al. Teneligliptin, a dipeptidyl peptidase-4 inhibitor, attenuated pro-inflammatory phenotype of perivascular adipose tissue and inhibited atherogenesis in normoglycemic apolipoprotein-Edeficient mice. Vascul Pharmacol. 2017;96-98:19-25.

65. Nakagami H, Pang Z, Shimosato T, Moritani T, Kurinami H, Koriyama $\mathrm{H}$, et al. The dipeptidyl peptidase- 4 inhibitor teneligliptin improved endothelial dysfunction and insulin resistance in the SHR/NDmcr-cp rat model of metabolic syndrome. Hypertens Res. 2014;37(7):629-35.

66. Sagara M, Suzuki K, Aoki C, Tanaka S, Taguchi I, Inoue T, et al. Impact of teneligliptin on oxidative stress and endothelial function in type 2 diabetes patients with chronic kidney disease: a casecontrol study. Cardiovasc Diabetol. 2016;15:76.

67. Okuda Y, Omoto S, Taniura T, Shouzu A, Nomura S. Effects of teneligliptin on PDMPs and PAI-1 in patients with diabetes on hemodialysis. Int J Gen Med. 2016;9:65-71.

68. Hashikata T, Yamaoka-Tojo M, Kakizaki R, Nemoto T, Fujiyoshi $\mathrm{K}, \mathrm{Namba} \mathrm{S}$, et al. Teneligliptin improves left ventricular diastolic function and endothelial function in patients with diabetes. Heart Vessels. 2016;31(8):1303-10.

69. JANUVIA ${ }^{\circledR}$ tablets $12.5,25,50,100 \mathrm{mg}$ interview form 2018. http://www.info.pmda.go.jp/go/interview/2/170050_3969010F10 34_2_025_1F.pdf. Accessed 10 Apr 2019.

70. Equa ${ }^{\circledR}$ tablets $50 \mathrm{mg}$ interview form 2016. http://www.info. pmda.go.jp/go/interview/1/300242_3969011F1020_4_EQA_1F. Accessed 29 Sep 2018.

71. NESINA ${ }^{\circledR}$ tablets $25 \mathrm{mg}, 12.5 \mathrm{mg}$ and $6.25 \mathrm{mg}$ interview form 2017. http://www.info.pmda.go.jp/go/interview/1/400256_39690 12F1025_1_012_1F. Accessed 29 Sep 2018.

72. TRAZENTA ${ }^{\circledR}$ tablets $5 \mathrm{mg}$ interview form 2018 . http://www.info. pmda.go.jp/go/interview/1/650168_3969014F1024_1_188_1F. Accessed 29 Sep 2018.

73. SUINY ${ }^{\circledR}$ tablets $100 \mathrm{mg}$ interview form 2018. http://www.info. pmda.go.jp/go/interview/1/300297_3969016F1023_1_009_1F. Accessed 29 Sep 2018.

74. ONGYZA ${ }^{\circledR}$ tablets $2.5,5 \mathrm{mg}$ interview form 2018. http:// www.info.pmda.go.jp/go/interview/1/230124_3969017F10 28_1_010_1F. Accessed 29 Sep 2018.

75. Zafatek ${ }^{\circledR}$ tablets $100 \mathrm{mg}$ and $50 \mathrm{mg}$ interview form 2018. http:// www.info.pmda.go.jp/go/interview/1/400256_3969024F10 28_1_004_1F. Accessed 29 Sep 2018.

76. MARIZEV ${ }^{\circledR}$ tablets $12.5,25 \mathrm{mg}$ interview form 2018. http:// www.info.pmda.go.jp/go/interview/1/170050_3969025F10 22_1_005_1F. Accessed 29 Sep 2018.

77. Amin M, Suksomboon N. Pharmacotherapy of type 2 diabetes mellitus: an update on drug-drug interactions. Drug Saf. 2014;37(11):903-19.

78. Karim A, Fleck P, Hetman L. Single-dose pharmacokinetics of the dipeptidyl peptidase-4 inhibitor alogliptin in subjects with renal impairment [abstract no. 538-P]. Diabetes. 2008;57:A160.

79. Graefe-Mody U, Friedrich C, Port A, Ring A, Retlich S, Heise $\mathrm{T}$, et al. Effect of renal impairment on the pharmacokinetics of the dipeptidyl peptidase-4 inhibitor linagliptin(*). Diabetes Obes Metab. 2011;13(10):939-46.

80. Boulton DW, Li L, Frevert EU, Tang A, Castaneda L, Vachharajani $\mathrm{NN}$, et al. Influence of renal or hepatic impairment on the pharmacokinetics of saxagliptin. Clin Pharmacokinet. 2011;50(4):253-65.

81. Graefe-Mody U, Retlich S, Friedrich C. Clinical pharmacokinetics and pharmacodynamics of linagliptin. Clin Pharmacokinet. 2012;51(7):411-27.

82. Shubrook J, Colucci R, Guo A, Schwartz F. Saxagliptin: a selective DPP-4 inhibitor for the treatment of type 2 diabetes mellitus. Clin Med Insights Endocrinol Diabetes. 2011;4:1-12.

83. Fuchs H, Runge F, Held HD. Excretion of the dipeptidyl peptidase-4 inhibitor linagliptin in rats is primarily by biliary excretion and P-gp-mediated efflux. Eur J Pharm Sci. 2012;45(5):533-8. 
84. TRADJENTA ${ }^{\circledR}$ (linagliptin): prescribing information. BoehringerIngelheim. Last updated; August 2017. http://docs.boehringer -ingelheim.com/Prescribing\%20Information/PIs/Tradjenta/Tradj enta.pdf?DMW_FORMAT=pdf. Accessed 20 May 2018.

85. Onglyza ${ }^{\circledR}$ (saxagliptin): prescribing information. AstraZeneca. Last updated: April 2018. https://www.azpicentral.com/onglyza/ pi_onglyza.pdf\#page $=1$. Accessed 14 Nov 2018 .

86. Lipska KJ, Krumholz H, Soones T, Lee SJ. Polypharmacy in the aging patient: a review of glycemic control in older adults with type 2 diabetes. JAMA. 2016;315(10):1034-45.

87. Solini A, Penno G, Bonora E, Fondelli C, Orsi E, Trevisan R, et al. Age, renal dysfunction, cardiovascular disease, and antihyperglycemic treatment in type 2 diabetes mellitus: findings from the Renal Insufficiency and Cardiovascular Events Italian Multicenter Study. J Am Geriatr Soc. 2013;61(8):1253-61.

88. Mizokami F, Koide Y, Noro T, Furuta K. Polypharmacy with common diseases in hospitalized elderly patients. Am J Geriatr Pharmacother. 2012;10(2):123-8.

89. Williams JA, Hyland R, Jones BC, Smith DA, Hurst S, Goosen TC, et al. Drug-drug interactions for UDP-glucuronosyltransferase substrates: a pharmacokinetic explanation for typically observed low exposure (AUCi/AUC) ratios. Drug Metab Dispos. 2004;32(11):1201-8.

90. Rendic S, Guengerich FP. Survey of human oxidoreductases and cytochrome P450 enzymes involved in the metabolism of xenobiotic and natural chemicals. Chem Res Toxicol. 2015;28(1):38-42.

91. Chung WG, Kang JH, Park CS, Cho MH, Cha YN. Effect of age and smoking on in vivo CYP1A2, flavin-containing monooxygenase, and xanthine oxidase activities in Koreans: determination by caffeine metabolism. Clin Pharmacol Ther. 2000;67(3):258-66.

92. Kanamori A, Matsuba I. Factors associated with reduced efficacy of sitagliptin therapy: analysis of 93 patients with type 2 diabetes treated for 1.5 years or longer. J Clin Med Res. 2013;5(3):217-21.

93. Kubota A, Yabe D, Kanamori A, Kuroe A, Takahashi N, Saito T, et al. Factors influencing the durability of the glucose-lowering effect of sitagliptin combined with a sulfonylurea. J Diabetes Investig. 2014;5(4):445-8.

94. Inagaki N, Harashima SI, Iijima H. Canagliflozin for the treatment of type 2 diabetes: a comparison between Japanese and non-Japanese patients. Expert Opin Pharmacother. 2018;19(8):895-908. 